\title{
Article \\ Multi-Attribute Decision Making for Energy-Efficient Public Transport Network Selection in Smart Cities
}

\author{
Rashmi Munjal *, William Liu, Xuejun Li ${ }^{(0)}$, Jairo Gutierrez $(\mathbb{1})$ and Peter Han Joo Chong * (]) \\ School of Engineering, Computer, and Mathematical Sciences, Auckland University of Technology, \\ Auckland 1142, New Zealand; william.liu@aut.ac.nz (W.L.); xuejun.li@aut.ac.nz (X.L.); \\ jairo.gutierrez@aut.ac.nz (J.G.) \\ * Correspondence: rashmi.munjal@aut.ac.nz (R.M.); peter.chong@aut.ac.nz (P.H.J.C.)
}

Citation: Munjal, R.; Liu, W.; Li, X.; Gutierrez, J.; Chong, P.H.J.

Multi-Attribute Decision Making for Energy-Efficient Public Transport Network Selection in Smart Cities. Future Internet 2022, 14, 42. https:/ / doi.org/10.3390/ fi14020042

Academic Editor: Davide Tosi

Received: 23 December 2021

Accepted: 20 January 2022

Published: 26 January 2022

Publisher's Note: MDPI stays neutral with regard to jurisdictional claims in published maps and institutional affiliations.

Copyright: (C) 2022 by the authors. Licensee MDPI, Basel, Switzerland. This article is an open access article distributed under the terms and conditions of the Creative Commons Attribution (CC BY) license (https:// creativecommons.org/licenses/by/ $4.0 /)$.

\begin{abstract}
Smart cities use many smart devices to facilitate the well-being of society by different means. However, these smart devices create great challenges, such as energy consumption and carbon emissions. The proposed research lies in communication technologies to deal with big datadriven applications. Aiming at multiple sources of big data in a smart city, we propose a public transport-assisted data-dissemination system to utilize public transport as another communication medium, along with other networks, with the help of software-defined technology. Our main objective is to minimize energy consumption with the maximum delivery of data. A multi-attribute decision-making strategy is adopted for the selction of the best network among wired, wireless, and public transport networks, based upon users' requirements and different services. Once public transport is selected as the best network, the Capacitated Vehicle Routing Problem (CVRP) will be implemented to offload data onto buses as per the maximum capacity of buses. For validation, the case of Auckland Transport is used to offload data onto buses for energy-efficient delay-tolerant data transmission. Experimental results show that buses can be utilized efficiently to deliver data as per their demands and consume 33\% less energy in comparison to other networks.
\end{abstract}

Keywords: big data; delay-tolerant network (DTN); multi-attribute decision making; public transport; energy consumption

\section{Introduction}

The smart city is being equipped with many smart devices, driven by the advancement of digital technologies and the ever-increasing demand of end-user applications. However, energy-efficiency is one of the recent demands toward the development of the green smart city. It is estimated that smart cities will be equipped with possibly 40,000 million smart devices for 100,000 million global connections in different areas, such as health care, transportation, and finance, etc. These smart devices will be responsible for generating big data in the smart city, which is already increasing at a compound annual growth rate (CAGR) of $47 \%$. It has been estimated that $90 \mathrm{ZB}$ of data will be created on IoT devices by 2025 [1].

As companies currently transfer massive amounts of data across wide-area networks to backup their data, sync search indexes between data centers, or provide high-definition surveillance video records to governments and access audio and video across social media sites, a large amount of data is transferred over wide-area networks. Since the data volume and complexity of big data [2] are extremely large, the survival of big data is impossible without the underlying technical support of networking. A new connectivity method is, therefore, required to overcome this biggest challenge. By finding alternative datatransmission network architectures, researchers aim to reduce traffic congestion. Cellular base stations, T2T approaches, WI-FI hotspots, and vehicular networks are a few examples of data offloading techniques used. Cities' bus networks [3] have characteristics such 
as wide coverage and fixed routes, granting them the potential to form the backbone of communication, alongside traditional networks.

In recent years, vehicular-assisted networks hold the utmost importance in the smart city to improve the quality of life, reliability, operational efficiency, and service quality in urban areas. Vehicles are used as data carriers in network communication. In addition to this, the data-offloading approach has been utilized to offload data from one network to another as per different criteria and priorities. Mobile Computation Offloading (MCO) [4] is a popular emerging technology to offload computation-intensive data to the servers to increase the capacity of devices and conserve battery energy. Through opportunistic contacts between moving vehicles and Road-Side Units (RSUs) placed on roads, it is possible to offload data onto vehicles for further delivery. In particular, public transport is a category of vehicular networks with several exclusive properties, such as regular and scheduled movements and reliable physical coverage in all urban centers.

The main contributions of this paper are the following:

1. We designed the Public Transport-Assisted Data-Dissemination (PTDD) System in a smart city which will be equipped with wireless sensors and data centers to handle massive data using wired, wireless, and public transport networks;

2. We applied a Multi-Attribute Decision making (MADM) algorithm for best network selection based upon different user requirements and different attributes;

3. We applied the Capacitated Vehicle Routing Problem (CVRP) to minimize energy consumption using public transport as a data carrier. We will use buses to offload the entire set of demands of each bus stop. Our model constrains the objective by the maximum capacity of the bus;

4. For the evaluation of the best network selection, different services are considered, based upon user requirements, to find the best network in the heterogeneous network. Next, a detailed comparative analysis of energy consumption is performed for traditional and public transport networks for the various demands of users.

The rest of the paper is organized as follows. The PTDD is presented in Section 2, along with MADM and CVRP, for network selection and for allocating data onto buses. In Section 3, we perform a numerical analysis and include two case studies to present the results. Next, we have a brief discussion section in Section 4. Finally, the paper is concluded in Section 5, along with a brief discussion about future work.

\section{Related Work}

Energy-efficient network technology is defined as the better utilization of resources whenever possible to alleviate network congestion. It has been estimated that $3 \%$ of the world's yearly electrical energy consumption, and $2 \%$ of CO2 emissions, are caused by information and communication technology (ICT) infrastructure [5]. Moreover, it is estimated that ICT energy consumption [6,7] is rising by 15-20 percent per year. Specifically, $57 \%$ of the energy consumption of the ICT business goes to users and network devices on mobile and remote networks [8]. The rapid development of energy consumption by the user and network devices has created major issues [9]; many efforts are being made by researchers for sustaining quality of services, throughput, and adaptability [10,11]. Devices, and their infrastructures, are arranged to obtain good QoS, and to provide better utilization of resources. The trade-off between execution and energy utilization should be exploited. The connection between energy and execution is indicated by [8]. The goal of energy efficiency is achieved through the use of virtualization, the consolidation of servers, and by upgrading older products to new, more energy-efficient ones.

Many co-operative data collection approaches from different locations have been proposed [12]. These approaches find [13,14] vehicles as optimal and logical links for transferring big data. Therefore, traditional homogeneous network communication, handoff algorithms, and data offloading are a few diverse applications [15] proposed to offload data onto different networks while considering different attributes. The public transport- 
assisted data-dissemination system can be interpreted as a delay-tolerant network where RSUs will be placed on each bus stop and communication between buses and RSUs occurs once the bus stops or passes by bus stops.

Before offloading data onto these buses, network selection is the critical process of identifying the best network in a heterogeneous network. This is possible with MultiAttribute Decision-Making (MADM) algorithms for appropriate decisions among different networks. There is a vast literature on MADM-based network-selection algorithms [16-18]. Many of these studies are user-centric and help to make decisions based on user preferences. There are many MADM algorithms for solving the network-selection problem, including AHP, GRA, SAW, MEW, TOPSIS, DIA, and ELECTRE [19]. Many researchers have discovered many other types of algorithms to resolve $\mathrm{VHO}$ and network-selection problems in heterogeneous networks. Some of them are utility functions [20], genetic algorithms [21], or use game theory principles [22]. Utility functions assign values as per the ranking of choices for the user's satisfaction. Abid et al. [23] proposed an innovative single-criteria utility function that used a metric for measuring user satisfaction as well as sensitivity to each decision criterion for deciding whether to hand over.

In [24], the researchers proposed a utility-based fuzzy-Analytic Hierarchy Process (AHP)-based network selection in heterogeneous wireless networks. They categorized different applications, such as voice, video, and best effort, and triangular fuzzy numbers were used to represent their comparison matrices. The results obtained prove that the MEW method yields better scores with utility functions. Jiang et al. [25] proposed a joint multi-criteria utility-based algorithm to assist the vehicle in infrastructure networking for energy efficiency. A user's preferences for different attributes, such as bandwidth, delay, signal intensity, and network cost, help to establish utility functions and an energy-efficient network-selection algorithm. Additionally, there have been some papers published on energy-efficient multi-connection for $5 G$ heterogeneous networks [26].

Michele et al. [27] explored the BUSNET algorithm that achieves effective routing in a bus environment. It considers routing at a bus-line level instead of a bus level. ALARMS [28] is one of the message-scheduling approaches that uses message ferries to forward messages and achieve good QoS. This publication [29] gives a promising solution, namely, "Cost-Effective Multimode Offloading"( CEMMO), that offloads data to the best possible choice among the following three options to reduce the overall cost in terms of energy efficiency, financial settlement, and user satisfaction. Kessar et al. [30] introduced the Always Best Connected (ABC) concept for always providing the best connectivity to all the applications. The handover decision is being taken on regrouping criteria such as network, terminal, user, and services. Another network-selection mechanism [31] was used in combination with AHP and GRA to trade off network circumstances, services, and user priorities. AHP was used for weighing based upon user preferences and GRA was used for ranking network alternatives. Liang et al. [32] introduced a user-oriented networkselection scheme, where five different modules are considered for network selection. One of them is an input which includes a utility function, and the other is a user-preference calculation using FAHP to calculate weighing of judgment. Yu et al. [33] proposed network selection using multi-service multi-modal terminals. They also used utility functions for multi-services for user satisfaction, network attributes, and service characteristics. In our previous work [3,34,35], we have introduced the use of a public transport network and offloaded data onto buses along with other networks for energy efficiency. We extended our work in the proposed manuscript with network selection and appropriate vehicle selection to offload data for energy efficiency.

\section{Public Transport-Assisted Data-Dissemination System}

The proposed framework depicts the Public Transport-Assisted Data-Dissemination System (PTDD), which consist of smart cities that are equipped with wireless sensors and data centers to handle massive data dissemination for several categories of applications, as shown in Figure 1, using a set of buses picked up at each bus stop. PTDD is composed of a 
central controller and a data center, along with RSUs deployed at bus stops and onboard units on buses. Smart meters, video surveillance data, and air pollution data are some of the delay-tolerant applications and can tolerate delays ranging from seconds, to minutes, to hours.

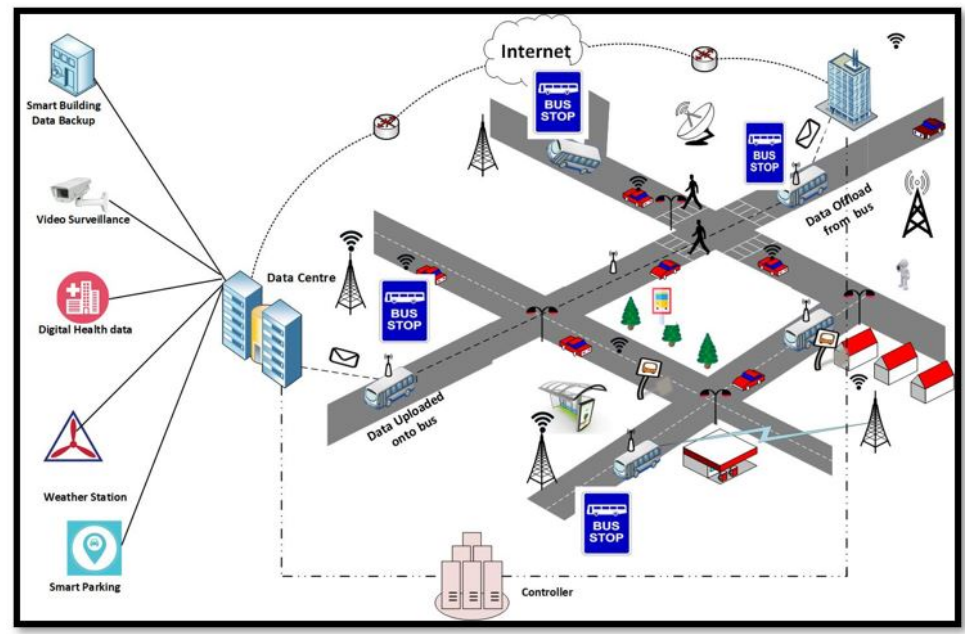

Figure 1. Public Transport-Assisted Data-Dissemination System (PTDD)

Over the last few years, we have witnessed the rapid growth of vehicles in urban areas together with the increase of internet-enabled devices integrated into vehicles [36]. Vehicles are being used as mobile nodes to create a mobile ad hoc network. They move randomly and communicate either with moving vehicles or fixed equipment such as RSUs. This alternative communications network layer of public transport networks will include public vehicles moving around the city. The flowchart given in Figure 2 gives an overview of the overall workflow of the proposed system. We will first apply the MADM methodology for the selction of the best network in the heterogeneous network, and next, we will offload data onto selected public vehicles to carry it until the destination for energy-efficient data transmission. 


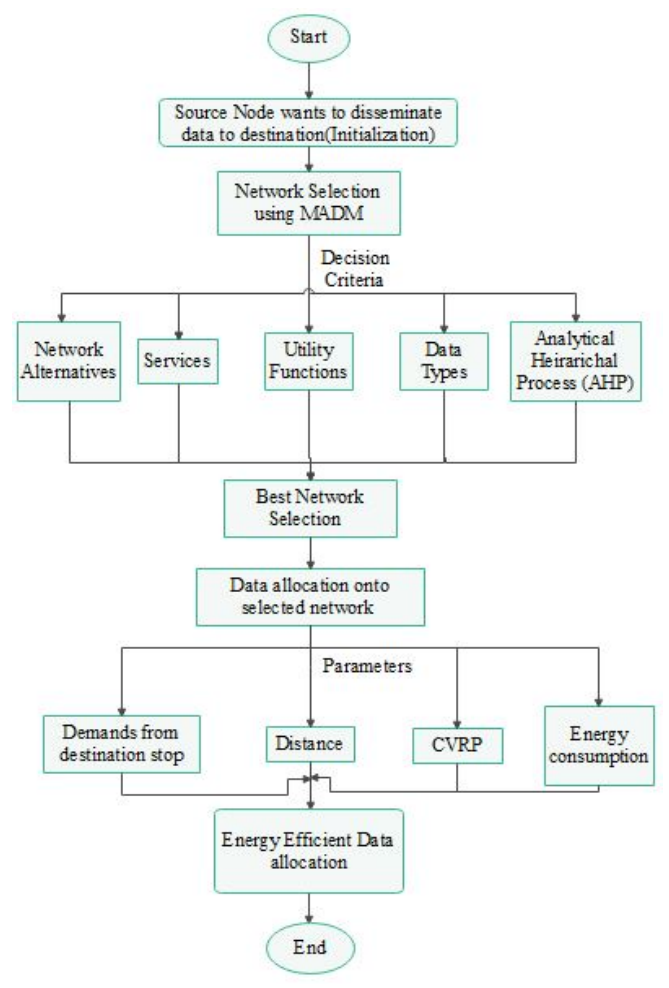

Figure 2. Flowchart of the proposed data-dissemination system.

\subsection{Multi-Attribute Decision Making}

MADM is being used for network selection among all the available networks. The network-selection procedure ultimately aims for the best network that can support the required service(s) and avoid excessive switching among different networks to minimize service interruptions and energy consumption. Therefore, we introduce the MADM method used by the controller in response to suitable network selection. This model helps to make forwarding decisions fairly. MADM is an important tool that assists in the solution of complex decision-making problems and analyzes network-selection problems in a heterogeneous network. There are a few characteristics of MADM given below:

(a) Alternatives: Alternatives are defined as several different options to prioritize or select. These can be called candidates, users, or networks, etc.;

(b) Decision Matrix: Any MADM problem can be mathematically defined by using a decision matrix, $L(M \times N)$ :

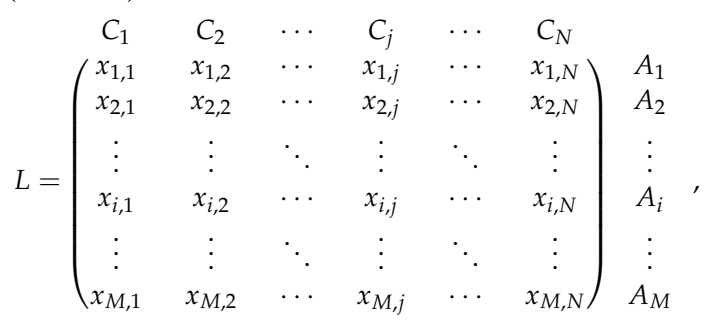

where $A_{1}, A_{2}, A_{3}, \ldots A_{i}, \ldots, A_{M}$ denotes all the alternatives/parameters to consider for decision making. $C_{1}, C_{2}, C_{3}, \ldots C_{j}, \ldots, C_{N}$ represents all $N$ criteria, which is being calculated as per different alternatives and denotes its performance. For example, $x_{i, j}$ is the performance ranking of the $i t h$ alternative w.r.t. to the $j t h$ alternative. The main aim of the decision matrix is to select the best alternative from the given alternatives with respect to others;

(c) Attribute Weight: Attribute weight is the value obtained by the decision-maker as per each attribute of the network. This weight depends upon the value assigned to the attribute. This weight is calculated by the pairwise comparison matrix; 
(d) Normalization: The attribute used for network selection has different measurement units. Therefore, normalization is a necessary step for this calculation.

MADM algorithms have high accuracy and low difficulty. They capture different parameters (e.g., QoS, bandwidth, delay, data volume, cost, etc.) and select the most suitable network. There are many possible solutions for MADM problems. The whole process of network selection is shown below, in Figure 3.

\subsubsection{Initialization Step}

The initialization step is the first-most step of the MADM process, which gathers the required information and triggers the process. In this step, there are the following options to consider:

- $\quad$ Service's Requirement: The most important aspect is the user's requirements. For different users, they have different demands and objectives. In our proposed system, we categorize users' requirements into three categories, such as Service 1, Service 2, and Service 3. Different services have different levels of sensitivity to the same networking attribute. For example, considering bandwidth as an attribute, if its service 1, a lower bandwidth will be used. However, if it is a large data transfer, a higher bandwidth will be used. In addition to that, it is assumed that a user can select any one service at one time. Users can select the priority of services used. They can select the urgency or non-urgency of data delivery, which relates to the data type, such as delay-tolerant or delay-sensitive, and helps the controller to make optimal network-selection decisions;

- Data Type: Data types belong to the type of application selected by users. It can be delay-tolerant or delay-sensitive. Some of the services, such as video or data type, can be categorized as a real-time or non-real-time application and can, accordingly, be delayed for some time. This is another important piece of information to consider for optimal network selection;

- $\quad$ Network Alternatives: In our proposed work, we are demonstrating the offloading of data from traditional networks to road networks with delay-tolerant conditions. Therefore, to choose among a list of networks, we will be considering WLAN, UMTS, and Vehicular Networks. The controller will choose the best optimal network among these networks based upon user requirements and data type. Three of these networks have different properties. The vehicular network is used for all delay-tolerant applications, such as emails, data backup, video download, and photos, which significantly contribute to energy efficiency without a negative effect on user satisfaction. We assume that all vehicles are equipped with On-Board Units (OBU) to carry data. If we compare the other two networks, WLAN networks are managed for higher bandwidths and lower delay applications, although UMTS networks are the most energy-efficient with lower bandwidth requirements and large delays. 


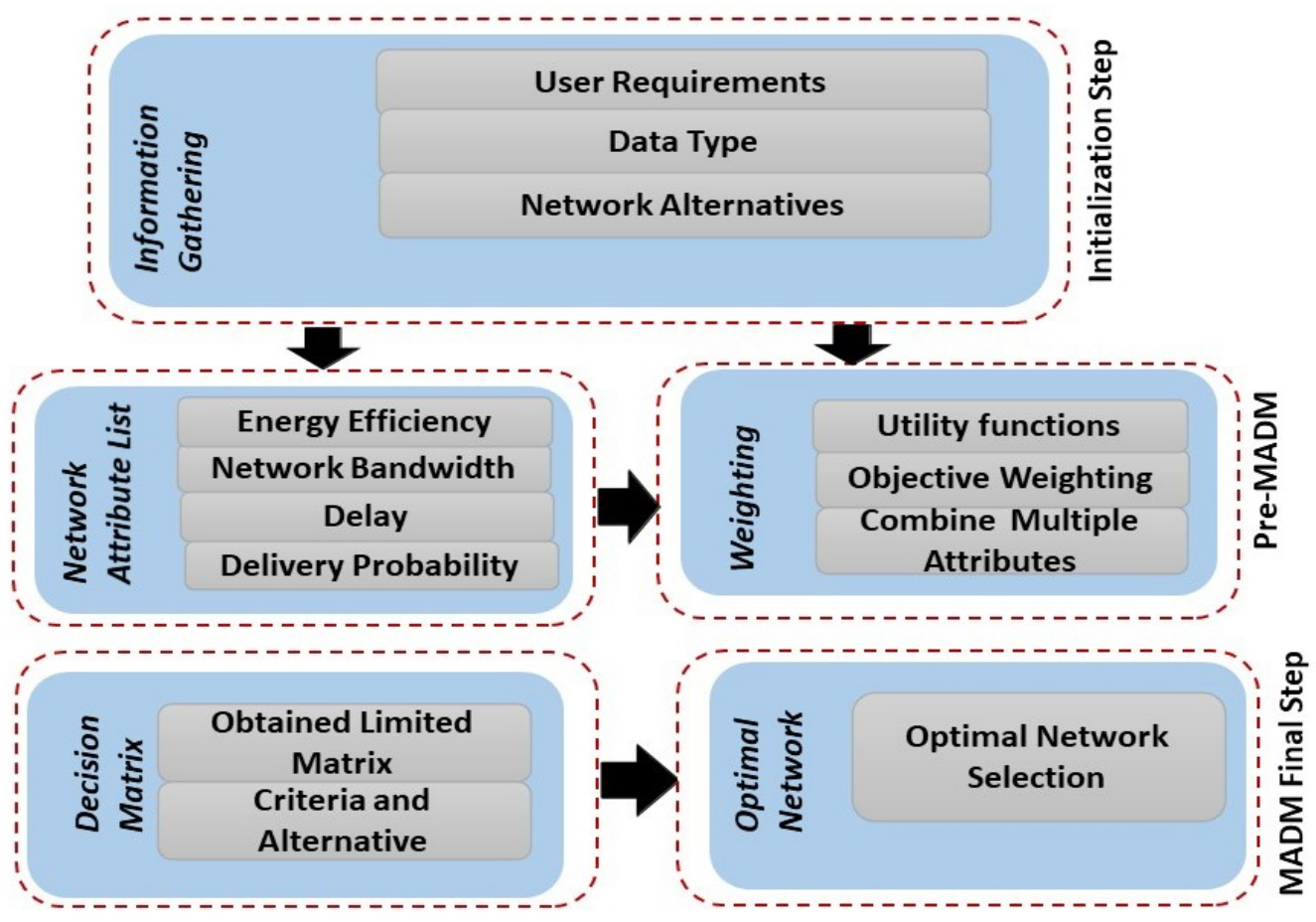

Figure 3. MADM for network selection.

Next, considering all the requirements in the process of network selection, we integrate utility theory with the AHP process to design our network-selection algorithm, as shown in Figure 4. We consider the characteristics of different types of services and their respective weights to define utility functions and the scores of a user's preferences by defining rank preference through AHP. Therefore, we are providing a comprehensive structure for users to give their preference, which the controller can use to make decisions based upon their requirements. 


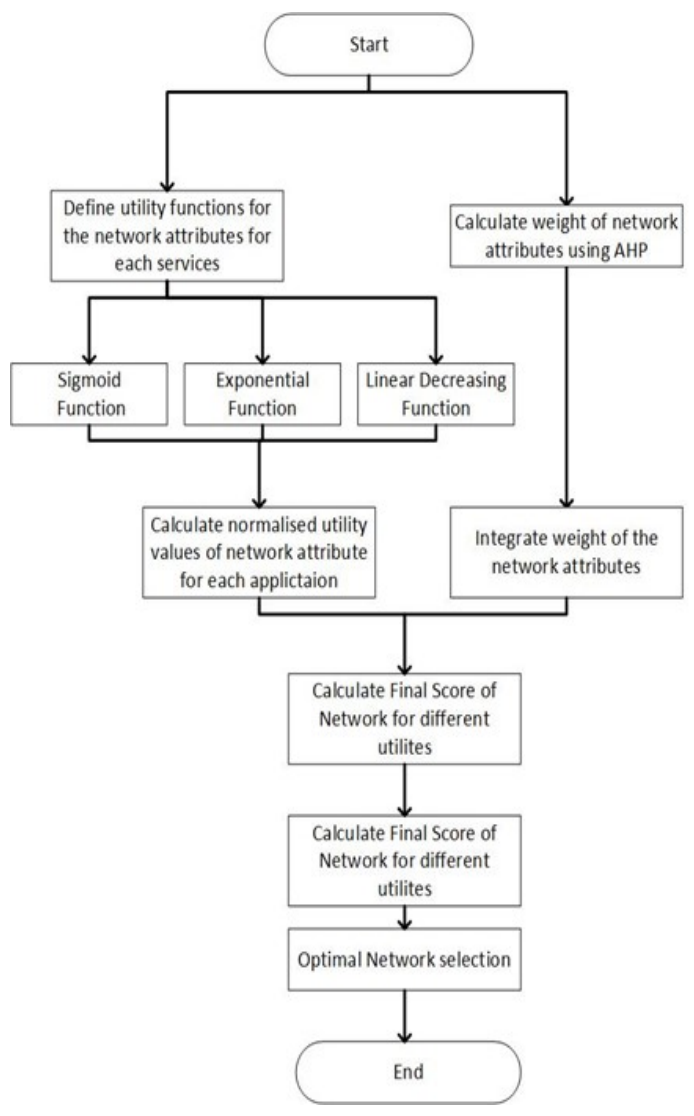

Figure 4. Flow chart of the proposed network-selection algorithm.

\subsubsection{Pre-MADM}

This step includes preparations before combining all the criteria, including the weighting and the attributes' adjustment procedures. The left part of this step is more about defining all the attributes to decide on the optimal network. The network attribute list consists of energy efficiency, delay-tolerant value, network bandwidth, and delivery probability. The right part of this step assigns utility values for each attribute, weighs different attributes against each other, and gives the best permutation to analyze optimal network selection. In our proposed method, users decide on all the requirements and importances. The controller collects these requirements and proceeds further with the weighing procedure. The measurement metrics for energy efficiency, delivery probability, network bandwidth, and delay are determined by these parameters appropriately.

- Utility function-theory-based network:

Utility functions measure the level of satisfaction for each user as per different attributes of each network alternative. We design utility functions to map decision factors to the respective utility metrics in order to evaluate the decision factors of network selection. We consider user requirements as per their profile, delay-tolerant indicator (DTI), both network properties, and QoS requirements. There are generally three types of utility functions that network selection uses: (1) sigmoid; (2) monotonically increasing; (3) linearly decreasing. These functions are further categorized as beneficial or non-beneficial criteria. The sigmoid utility function is used with given minimum and maximum requirements. Bandwidth and energy efficiency are beneficial criteria and can be represented as a sigmoid function. The utility theory states that utility functions must satisfy twice differentiability, monotonicity, and concavityconvexity [37]. Therefore, we design different utility functions for different objectives. The value of the utility function lies between 0 and 1 . For the most satisfied user, it is 1 , and for the least satisfied user, it counts as 0 . 
- Utility function for Energy Efficiency EE: In this utility function, EE, as discussed, is a beneficial criterion, and the energy-efficient utility function will be modeled as a sigmoid curve. The sigmoidal utility function is defined below:

$$
u(e)=\frac{1}{1+x e^{c\left(e_{\text {avg }}-e\right)}} ; e>0,
$$

where $e_{a v g}$ and $e$ represent the average network energy efficiency and network energy efficiency; $x$ is used as a constant value that is always greater than zero $(x>0)$. The notation $c$ is used to denote the sensitivity of network attributes affecting energy efficiency. The utility function for EE is plotted in Figure 5; we can make sure that the utility function is monotonic and concave-convex. In physical terms, Equation (2) is the result of a higher network energy efficiency, with $e$ translating into a larger utility function, $u(e)$, resulting in a more preferred network.

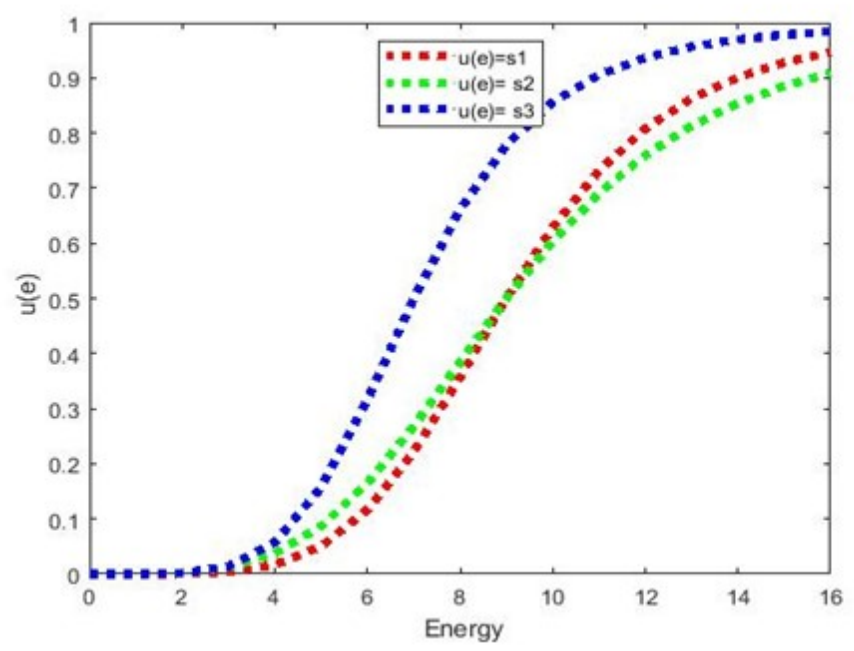

Figure 5. The utility function for energy efficiency.

- Utility function for Network Bandwidth: Network Bandwidth is an important attribute for network selection. For three of these networks, the network bandwidth has a different value. When the network bandwidth is lower than the required bandwidth, as per different service requirements, then there is a compromise in QoS, and there will be a loss of packets. We are using the following utility function to define bandwidth requirements for different applications:

$$
u(b)= \begin{cases}0, & ; b<b_{\text {min }} \\ \frac{\left(\frac{b}{b_{\text {med }}}\right)^{x 4}}{1+\left(\frac{b}{b_{\text {med }}}\right)^{x 4}} & ; b \leq b_{\text {min }} \leq b_{\text {med }} \\ 1-\frac{\left(\frac{b_{\text {max }}-b}{b_{\text {max }}-b_{\text {med }}}\right)^{x 4}}{1+\left(\frac{b_{\max }-b}{b_{\text {max }}-b_{\text {med }}}\right)^{x 4}} & ; b_{\text {med }} \leq b \leq b_{\text {max }} \\ 1 & ; b>b_{\text {max }}\end{cases}
$$

where $b_{\min }$ and $b_{\max }$ define the minimum and maximum bandwidths of each network. In addition, $b$ is the actual bandwidth required by the user, as per the services required. This is the same as an energy utility function. All the utility functions fulfill the conditions of being is twice differentiable, monotonic, and concave-convex, as shown in Figure 6. 


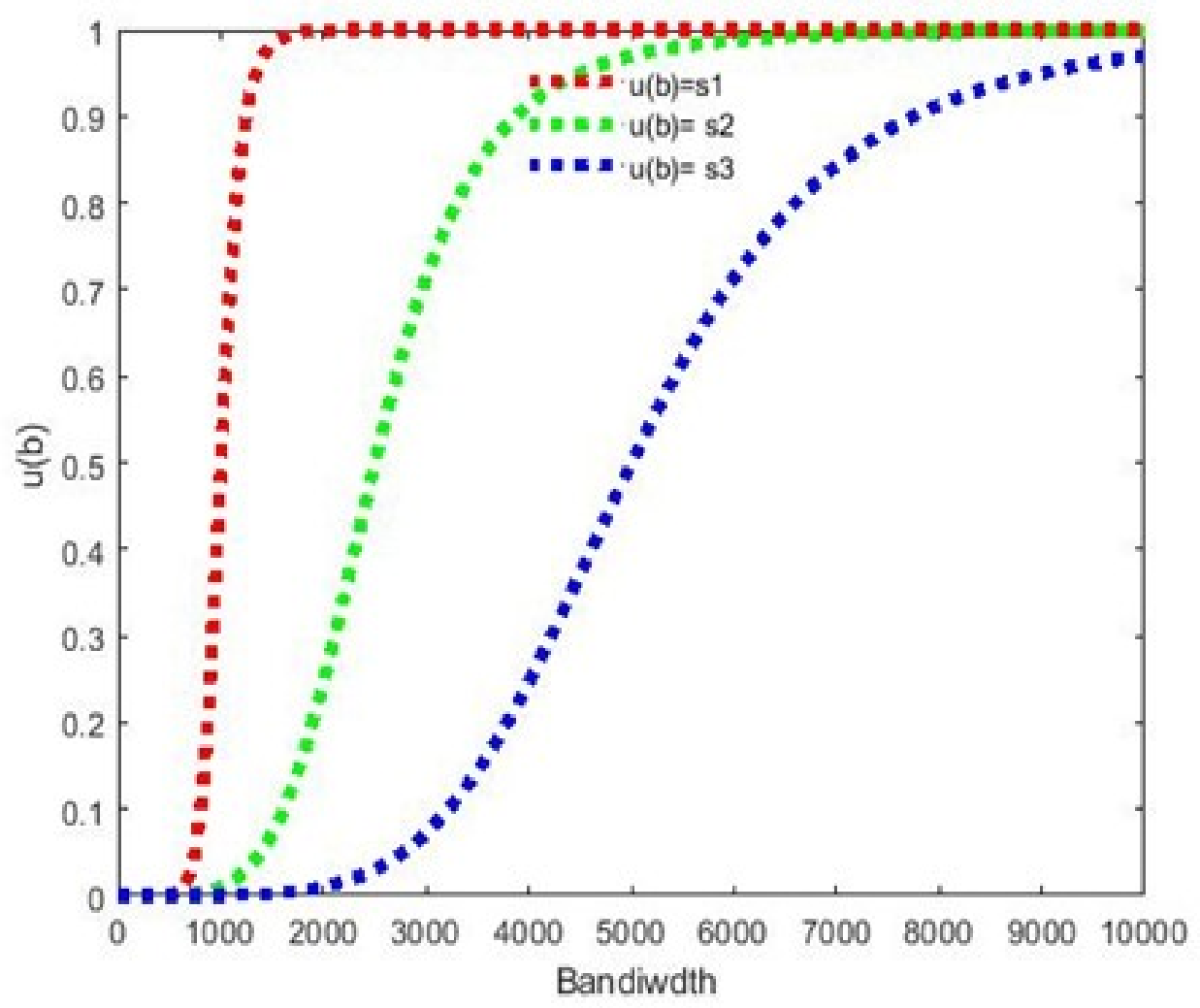

Figure 6. The utility function for Bandwidth.

- Utility function for Delay Tolerance: Generally, incremental latency values are acceptable in a Delay-Tolerant Networks (DTN). While designing the utility function for network delay tolerance, a larger network delay value will result in a lower utility value. It is a decreasing criterion to measure network delay. Delay varies in both networks as per the data volume. $u(d)$ is defined as a utility function for the delay, as below:

$$
u^{\prime}(d)= \begin{cases}\frac{\left(\frac{d}{d_{\text {med }}}\right)^{x 3}}{1+\left(\frac{d}{d_{\text {med }}}\right)^{x 3}} & ;(d)=1-u^{\prime}(d) \\ 1-\frac{\left(\frac{d_{\text {max }}-d}{d_{\text {max }}-d_{\text {med }}}\right)^{x 3}}{1+\left(\frac{d_{\text {max }}-d}{d_{\text {max }}-d_{\text {med }}}\right)^{x 3}} & ; d_{\text {med }} \leq d \leq d_{\text {med }} \\ 1 & ; d>d_{\text {max }}\end{cases}
$$

where $d_{\text {max }}$ is the maximum delay and $x$ is the sensitivity factor for delay calculation among both networks. The delay utility function is shown in Figure 7. 


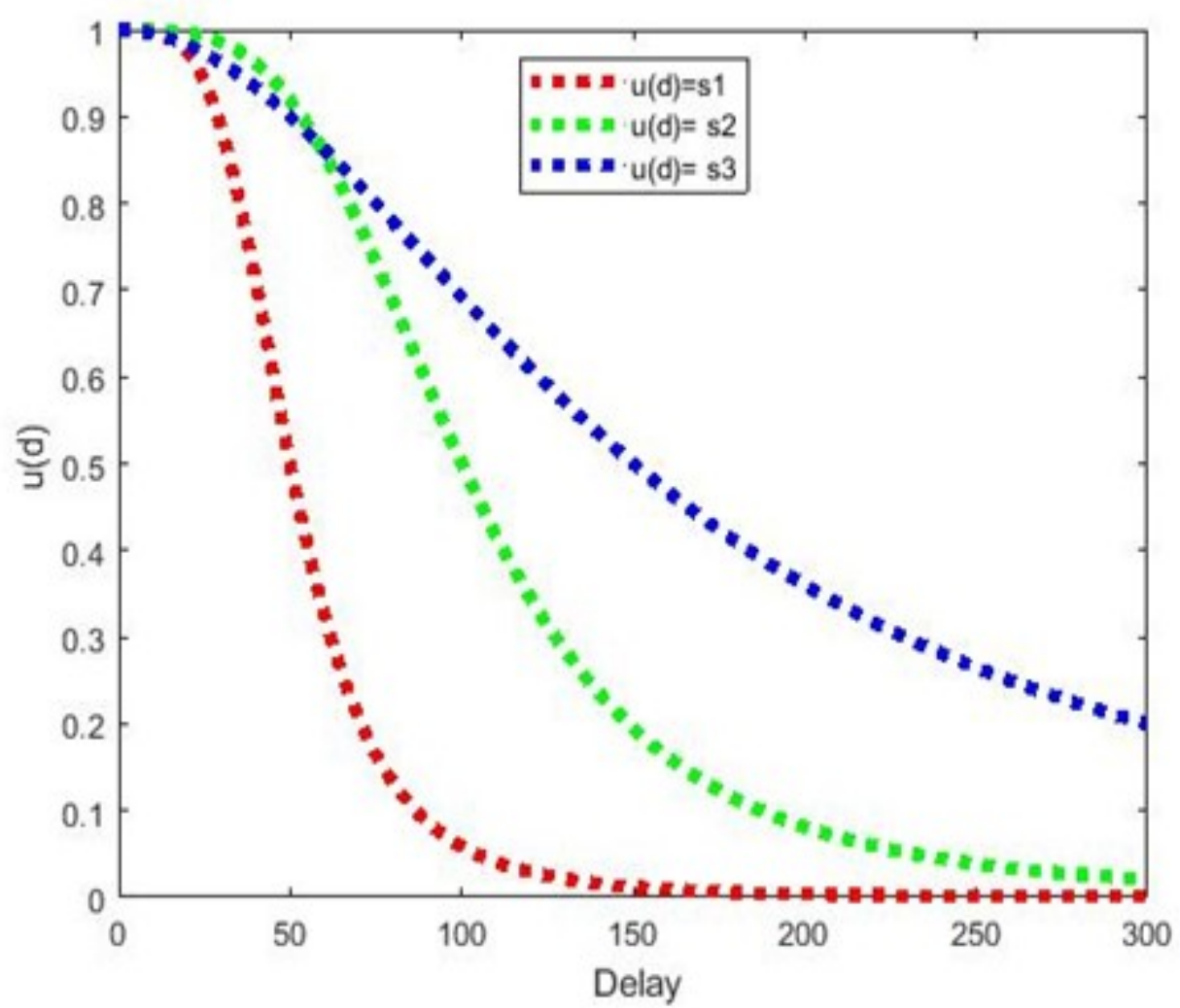

Figure 7. The utility function for delay tolerance.

- Utility function for the Delivery Probability: Delivery probability is to be defined as the volume of data to be sent using any of the networks. We defined the utility function of delivery probability as $u(d p)$, where $d p \epsilon[0,1]$, in case of successful delivery, is 1 , and otherwise, for packet loss, it will be considered as 0 . Otherwise, it lies between 0 and $1 . d p$ is the delivery probability obtained and $d p_{\max }$ is the maximum delivery probability that is acceptable to the user, and is shown in Figure 8.

$$
u(d p)= \begin{cases}\frac{d p}{d p_{\max }} & ; 0 \leq d p \leq d p_{\max } \\ 1 & ; d p>d p_{\max }\end{cases}
$$

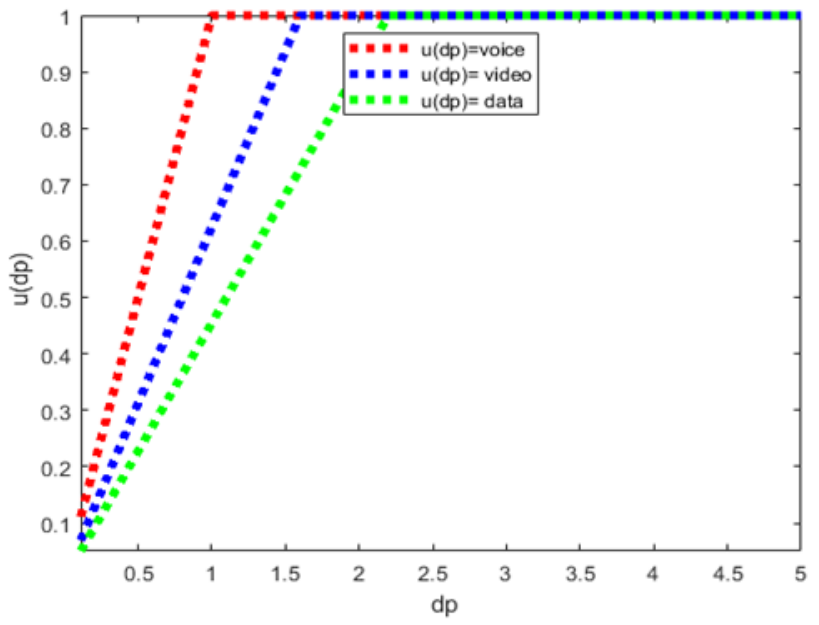

Figure 8. The utility function for delivery probability. 


\subsubsection{MADM}

This step helps with deciding between different networks, based on the weights obtained from the decision matrix, the alternatives, and different criteria.

- Analytical Hierarchical Process

The analytical Hierarchical process (AHP) method is a multi-criteria decision-making process for network selection. It was developed at the Wharton School of Business by Thomas Saaty in the 1970s [38]. AHP works on the function of priority and rank to evaluate subjective weights to achieve the specified goals. We have used this process to select a best-featured network from the given alternatives for the given service class based on the following criteria-Energy Consumption, Bandwidth, Delay, and Delivery Probability. We have also used this process for choosing a priority of network types for each data type. Network weighing is an important factor to characterize the network performance and user's preferences. We use the hierarchy analysis method to allocate the appropriate weight to each selection metric.

We further categorize traditional networks into WLAN and UMTS networks for impartial scheming with different attributes, as shown in Figure 9. The logical flowchart of the AHP algorithm considers the hierarchical structure with the main goal, multiple criteria, and network alternatives to select. We have defined utility functions for all the attributes for a network assessment. A user's preference will be based on multiple criteria for network selection. We assume that WLAN users have wireless access to their system, but with a fixed location —or we can say a local network —and that they use all their devices to avail the services and disseminate data to nearby RSUs for further transmission. However, they have good speed and bandwidth values. On the other hand, UMTS is a mobile cellular device and can roam around with their data plans, but with limited bandwidths and larger delays as per the delivery probability and data network's range.

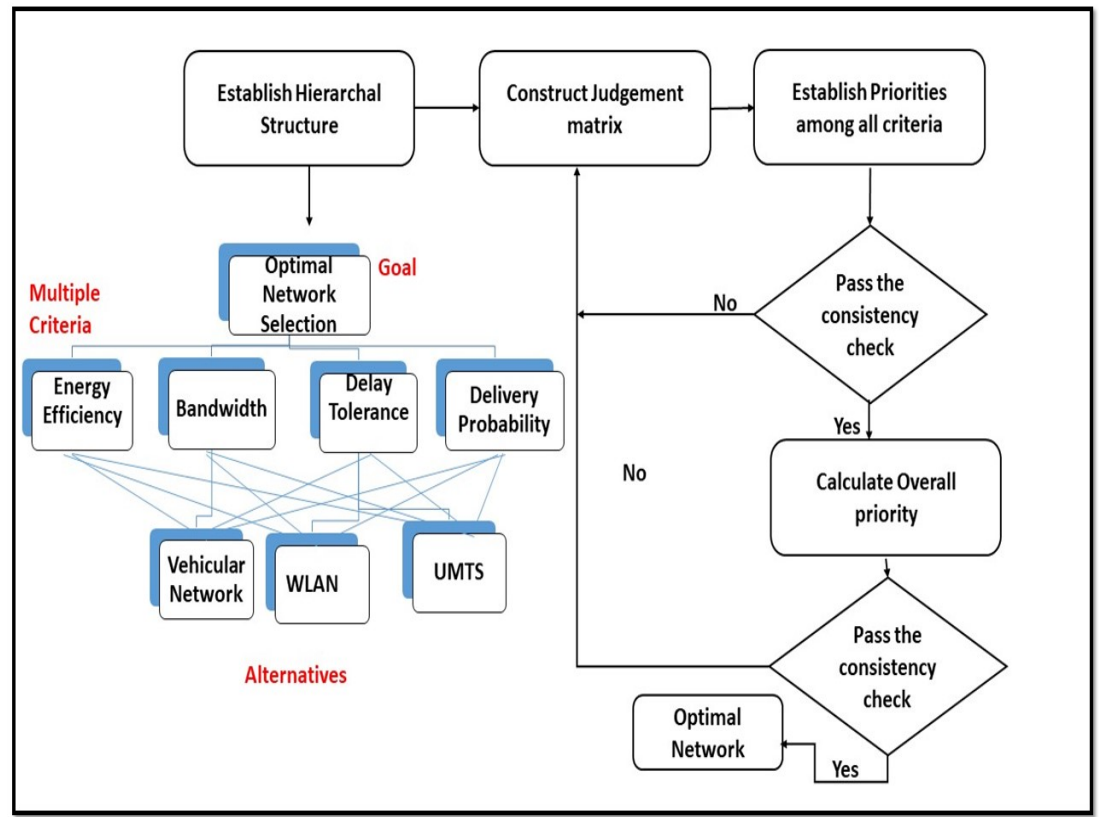

Figure 9. AHP for network selection.

1. Subdivide a problem into further sub-problems by defining an objective function, criteria, and possible alternatives. Here, the objective is our goal of achieving optimal network selection. The multiple criteria are the factors affecting the preference for selection.

2. Develop the hierarchy model of all objectives along with their elements to obtain the priorities of criteria through pairwise comparison matrices. 
3. Construct a pairwise comparison matrix for each criterion of hierarchical structure in such a way that all associated criteria are compared with each other as per the intensity of importance [39], with respect to the scale. We believe that a pairwise comparison between alternatives helps for qualitative judgment. This qualitative pairwise comparison follows the importance scale, as shown in Table 1.

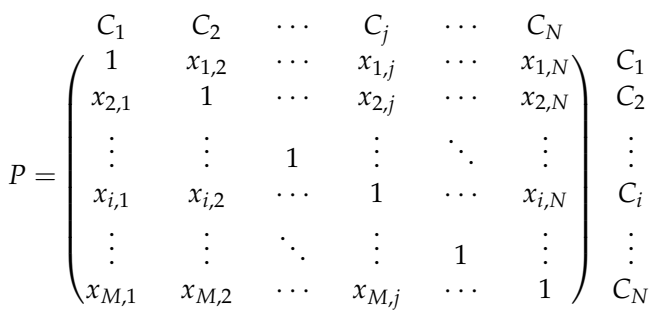

Table 1. Criteria importance scale in a pairwise comparison.

\begin{tabular}{cc}
\hline Preferences as per Importance & Definition \\
\hline 1 & Equal Importance \\
\hline 3 & Moderate importance \\
\hline 5 & Strong importance \\
\hline 7 & Very strong importance \\
\hline 9 & Extreme importance \\
\hline $2,4, \ldots, 8$ & Intermediate values \\
\hline
\end{tabular}

4. Perform the normalization of a given matrix $P$, which is now denoted as $P_{\text {Norm }}$ :

$$
\begin{aligned}
& P_{\text {Norm }}=\left(\begin{array}{ccccccc}
C_{1} & C_{2} & \ldots & C_{j} & \cdots & C_{N} & \\
z_{2,1} & z_{1,2} & \cdots & z_{1, j} & \cdots & z_{1, N} & C_{1} \\
\vdots & \vdots & 1 & \vdots & \ddots & \vdots & \vdots \\
z_{i, 1} & z_{i, 2} & \cdots & 1 & \cdots & z_{i, N} & C_{i} \\
\vdots & \vdots & \ddots & \vdots & 1 & \vdots \\
z_{M, 1} & z_{M, 2} & \cdots & z_{M, j} & \cdots & 1
\end{array}\right) C_{N} \\
& \text { where, } z_{i, j}=\frac{x_{i, j}}{\sum_{i=1}^{N} x_{i, j}} \text {. }
\end{aligned}
$$

5. The contributions of each normalized metric are multiplied by the assigned importance weight wj, and can be calculated for the ith criteria, as below:

$$
P_{w}=\frac{\sum_{i=1}^{N} Z_{i, j}}{N} \text { with } \sum_{i=1}^{N} P_{w}=1,
$$

such that $P_{w}$ is the weight vector.

6. Calculate the consistency index, where $\lambda_{m}$ ax is the largest eigenvalue of $P_{\text {Norm }}$, and it is determined from the eigenvalue computation of $P_{\text {Norm }}$ :

$$
C I=\frac{\lambda_{\max }-N}{N-1}
$$

7. In the last step, evaluate the consistency of the comparison using the Consistency Ratio (CR), defined as: 


$$
C R=\frac{C I}{R I}
$$

where $R I$ [31], as defined in Table 2, is the index used for the number of attributes used in decision making; the network is ranked based on this index. For acceptable results, $C R<0.1$; otherwise, pairwise comparison should be repeated.

Table 2. The random index.

\begin{tabular}{ccccccccccc}
\hline $\mathrm{N}$ & 1 & 2 & 3 & 4 & 5 & 6 & 7 & 8 & 9 & 10 \\
\hline $\mathrm{RI}$ & 0 & 0 & 0.58 & 0.9 & 1.12 & 1.24 & 1.32 & 1.41 & 1.45 & 1.49 \\
\hline
\end{tabular}

In such a way, AHP helps with network selection among different networks based upon different attributes. After the selection of the public transport network, the next section will elaborate further about allocating data onto buses as per their stay-time at each bus stop.

\subsection{Capacitated Vehicle Routing Problem (CVRP)}

Once we select the best network in terms of energy efficiency. It is important to know which vehicle can be more energy-efficient when we allocate data onto buses at each bus stop. As shown below, in Figure 10, the source data center accumulates all the data from nearby user devices and caches it until an optimal bus is not found for the destination route. At each bus stop, RSUs have been deployed to offload data onto buses, and these buses carry data until the destination bus stop and upload onto the destination bus stop and to the data center.

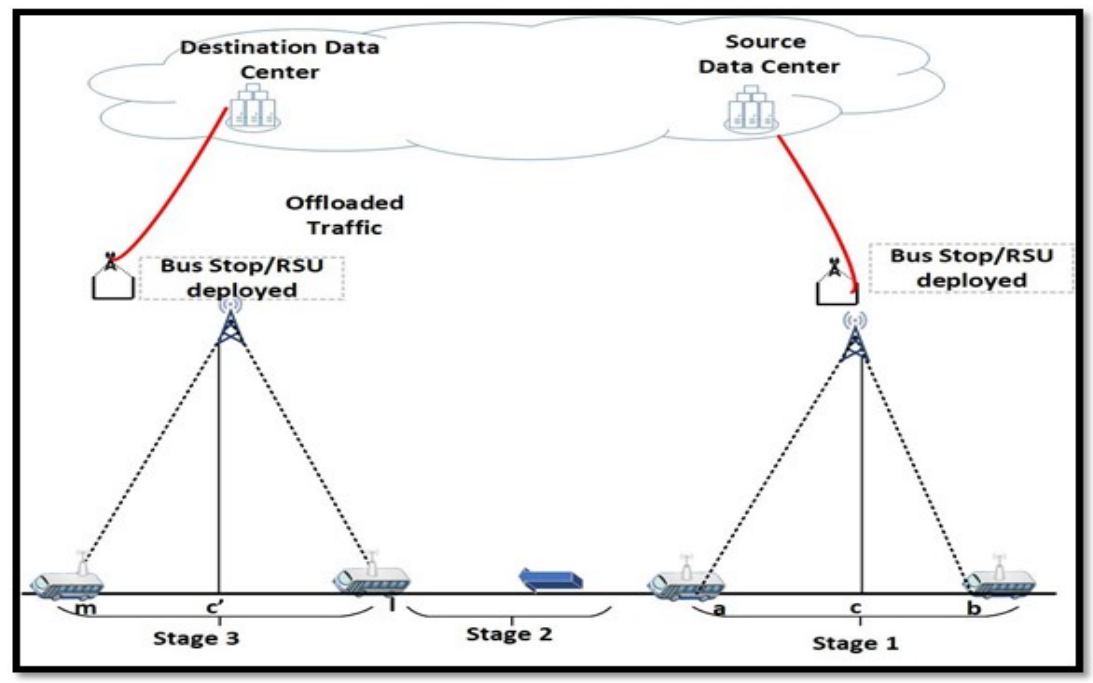

Figure 10. CVRP problem for data allocation.

We will take different demands from the data center (DC) to allocate data onto buses as per their maximum capacity to carry data until reaching the destination while minimizing energy consumption. We will, first, define CVRP to minimize energy consumption while using public transport as a data carrier.

In our model, all demands are allocated by the controller to the appropriate bus going in that direction. The demands are fetched from the DC and are allocated to the bus going on a trip in the direction of the destination location. Note that data offloading/uploading is possible at each bus stop; therefore, the transmission range is expected to be limited for data offloading onto these buses. The whole transmission procedure and energy consumption is calculated in three stages: 
Stage 1: RSU-Bus transmission: When the bus stops at the parent stop or source data center, data is allocated onto the bus within the transmission range. As shown in Figure 10, $\mathrm{a}$ and $\mathrm{b}$ are the earliest and final points for stage 1 . Point $\mathrm{c}$ denotes the central projection when the bus stops at the bus stop;

Stage 2: Stable State: In stage 2, the bus will carry data, as per demands, on its fixed route and does not consume any extra energy, and will consume negligible energy.

Stage 3: Bus-RSU transmission: In stage 3, the bus reaches the destination spot and uploads data onto the bus stop. 1 and $\mathrm{m}$ are the initial and final points of this stage, and $\mathrm{c}^{\prime}$ is the vertical projection of RSU deployed at the destination bus stop. We will minimize energy consumption by offloading data onto the fixed bus with a fixed capacity to carry data and, thus, finding the optimal solution.

- $\quad$ Problem Definition

To offload data onto buses, there is n number of demands being fulfilled by a DC, and a nearby stop is a depot to start the bus journey and return to the same bus stop after finishing its route. B is the set of buses, CB is the capacity of the bus, D is the deadline for the message delivery, which also considers the number of trips being taken by a bus. Each DC has different demands di for different locations. We define our problem in a graph $G(V, E)$, where $V=0,1,2 \ldots n$ is a set of all nodes of the graph and $E$ is the set of edges $(i, j) \ldots(I, j) \in N$. Arc $(i, j)$ represents the path from node $i$ to node $j$. The energy cost $\left(E_{i, j}\right)$ is calculated for each bus to carry data from the source until the destination. The minimum number of buses required to fulfill all the demands is $\frac{\sum_{i=1}^{n} d_{i}}{C_{B}}$. The controller will assign demands onto each bus as per the destination location. A CVRP can be formulated as follows:

Objective: To minimize

$$
\sum_{b \in B} \sum_{i=1}^{n} \sum_{j=1}^{n} E_{i, j} X_{i, j, b},
$$

which minimizes the total energy consumption cost of buses. There are various constraints subjected to this function, defined below:

Subjected to:

$$
\begin{aligned}
& \sum_{i=1, i \neq j}^{n} \sum_{b \in B} X_{b, i, j}=1 \quad \forall j=1, \ldots . n \\
& \sum_{j=1}^{n} X_{b, 0, j}=1 \quad \forall b \epsilon\left(B_{1}, B_{2}, \ldots . . B_{n}\right) \\
& \sum_{i=1, i \neq j}^{n} X_{b, i, j}=\sum_{i=1}^{n} X_{b, i, j} \quad \forall j=1, \ldots . . n, \quad b \epsilon\left(B_{1}, B_{2}, \ldots . B_{n}\right) \\
& \sum_{i=1}^{n} \sum_{j=1, i \neq j}^{n} d_{j} X_{b, i, j} \leq C_{B} \quad \forall b \epsilon\left(B_{1}, B_{2}, \ldots . B_{n}\right) \\
& \sum_{b=B_{1}}^{B_{n}} \sum_{i \in T} \sum_{j \in T, i \neq j} X_{b, i, j} \leq|T|-1 \quad \forall T \subseteq(1, \ldots . . n) \\
& X_{b, i, j} \epsilon(0,1) \quad \forall b \epsilon\left(B_{1}, B_{2}, \ldots . . B_{n}\right) ; i, j=(1, \ldots . n)
\end{aligned}
$$

where $X_{(i, j, b)}$, the binary variable, defines a set of buses $b \epsilon B_{1}, B_{2} \ldots B_{n}$, that traverses an $\operatorname{arc}(i, j)$. The objective function, defined in equation 13, minimizes the energyconsumption cost. Constraint 14 is the degree constraints, confirming that each demand will be fulfilled by an available bus. Each bus starts its trip from the parent stop, where data is offloaded, delivers data at the destination, and finishes the trip at the same stop as shown in constraint 15 and 16. Constraint 17 defines the maximum 
capacity of the bus to carry data. All the demands of the DC are fulfilled by the available buses of the day. Constraint 18 defines that, as per the defined time, there are no cycles disconnected to the parent stop. The definition domains of the variables are described in constraint 19.

\section{Numerical Analysis and Results}

Firstly, to evaluate the best network selection, we will consider the Auckland public transport network to choose among three network alternatives. The reason for choosing Auckland as a case study is that Auckland has a vision to be the world's most liveable city with smart citizens and a smart infrastructure. Auckland is a city with innovative technologies to improve the quality of life. Auckland, as a smart city, can think of smart and innovative devices to make decisions based on real-time data analysis. Seven New Zealand projects have been short-listed in IDC's Asia Pacific Smart Cities Awards [40]. Considering all the facts, Auckland Transport was a good example to validate our proposed system. Normally, the urban area is covered by heterogeneous wireless networks, including WLAN, UMTS, and Public Vehicles/buses. All these networks bear different characteristics, as described above. For vehicular network selection, the vehicle must be in the range of the network to consider it a selection option, based upon the user's preference. For simplification, we make the following assumptions:

Assumption 1. We consider three types of networks: WLAN, UMTS, and vehicular networks. For further information related to the vehicular network, only scheduled public transport vehicles are involved. WLAN and UMTS networks covers the whole region, while VANET covers partially, only within a specified range of bus stops. Additionally, vehicle-to-vehicle communication is not considered;

Assumption 2. For any of the network selections, there is a predefined bandwidth and range-defined network selection is only possible if those conditions are met. Every user has different preferences based on their requirements. We will use the AHP method to assess each user's requirements and preferences.

\subsection{Case Study I}

We will consider Auckland Central as shown in Figure 11 as an area for data analysis and as the locations to show the vehicle's distribution among different bus stops. We have considered four different locations: City Center, Britomart, Wellesley Street, and Auckland Hospital. All of these bus stops are equipped with local storage for data storage to upload or download onto buses on that route. Furthermore, all users' profiles are checked, as per the source and destination location of the data transmission, and buses are selected based upon that.

We will evaluate the performance of the AHP method using simulations over MAT$\mathrm{LAB}$, based upon different utility values for all attributes. We simulate for our goal to have optimal network selection based upon different criteria and alternatives. User preferences play an important role in the selection of the best available network in a heterogeneous environment. The proposed method for determining the user's preference is based upon the basic idea of AHP. 


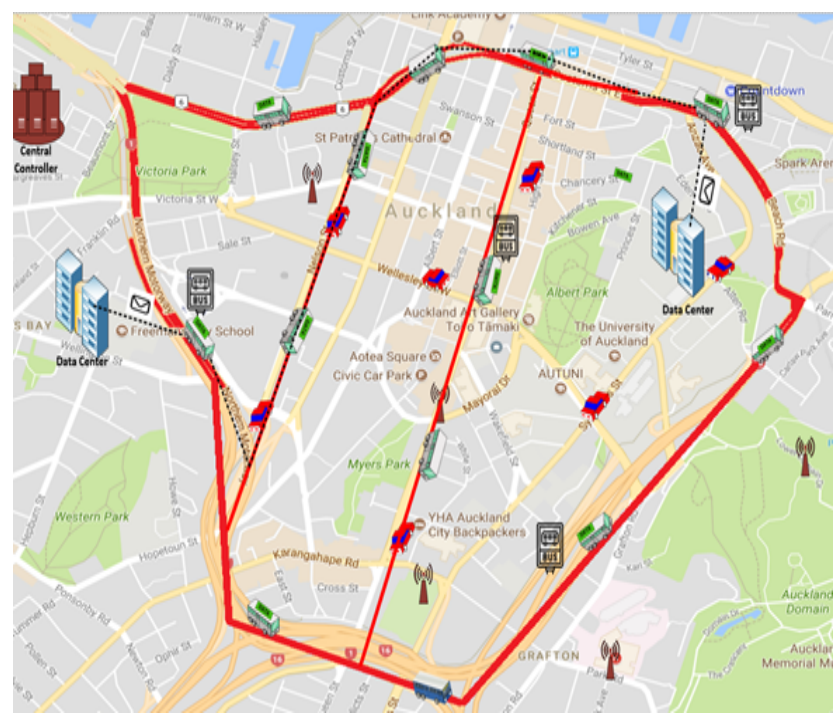

Figure 11. Auckland Central map with locations.

\subsubsection{Service 1}

We have categorized our services with all the different criteria as defined below. The first service is to be initialized from the data center (DC1) to the data center (DC2). The controller helps to select the optimal network as per their preferences being decided for different criteria defined above, such as Energy Efficiency (EE), Bandwidth (B), Delivery probability (DV), and Delay Tolerance (DT). The utility values have been defined for all attributes in Section 2, above.

$$
S_{1}=<E E, B D V, D T>
$$

In this Service $1\left(S_{1}\right)$, we assume that this service is for non-real-time applications, such as video surveillance data, that are accumulated at the data center and that can be delayed for up to 13 hours. There are three possible networks to choose from: UMTS, WLAN, and public transport. When the end-user sends and receives big data files, such as backup storage or large datasets, in TB or PB, this scheme applies. The scheme is, thus, more or less delay-tolerant, for example, background downloading of email messages, sending of data with Google Grive, and data backup. In this case, we give more importance to the energy-efficiency factor than other attributes, as we can bear delays for these applications or services. Now, the same procedure will be followed for all the attributes as per services, as defined in Tables 3-5.

Table 3. Pairwise Comparison Utility matrix as per importance scale.

\begin{tabular}{ccccc}
\hline Attributes & $\begin{array}{c}\text { Energy } \\
\text { Efficiency }\end{array}$ & Bandwidth & $\begin{array}{c}\text { Delay } \\
\text { Tolerance }\end{array}$ & $\begin{array}{c}\text { Delivery } \\
\text { Probability }\end{array}$ \\
\hline Energy Efficiency & 1 & 7 & 9 & 3 \\
\hline Bandwidth & $1 / 3$ & 1 & 7 & 2 \\
\hline Delay Tolerance & $1 / 9$ & $1 / 7$ & 1 & $1 / 5$ \\
\hline Delivery probability & $1 / 3$ & $1 / 2$ & 5 & 1 \\
\hline
\end{tabular}


Table 4. Normalized score table for all the attributes with the weight factor.

\begin{tabular}{cccccc}
\hline Attributes & $\begin{array}{c}\text { Energy } \\
\text { Efficiency }\end{array}$ & Bandwidth & $\begin{array}{c}\text { Delay } \\
\text { Tolerance }\end{array}$ & $\begin{array}{c}\text { Delivery } \\
\text { Probability }\end{array}$ & $\begin{array}{c}\text { Critera } \\
\text { Weight }\end{array}$ \\
\hline Energy Efficiency & 1 & 7 & 9 & 3 & 0.530345069 \\
\hline Bandwidth & $1 / 3$ & 1 & 7 & 2 & 0.164911216 \\
\hline Delay Tolerance & $1 / 9$ & $1 / 7$ & 1 & $1 / 5$ & 0.041457905 \\
\hline Delivery probability & $1 / 7$ & $1 / 2$ & 5 & 1 & 0.280751063 \\
\hline
\end{tabular}

Table 5. Normalized score table with priority vector.

\begin{tabular}{ccccccc}
\hline Attributes & $\begin{array}{c}\text { Energy } \\
\text { Efficiency }\end{array}$ & Bandwidth & $\begin{array}{c}\text { Delay } \\
\text { Tolerance }\end{array}$ & $\begin{array}{c}\text { Delivery } \\
\text { Probability }\end{array}$ & $\begin{array}{c}\text { Critera } \\
\text { Weight }\end{array}$ & $\begin{array}{c}\text { Priority } \\
\text { Vector } \\
\left(\boldsymbol{P}_{\boldsymbol{w}}\right)\end{array}$ \\
\hline Energy Efficiency & 1 & 3 & 9 & 7 & 0.530345069 & 0.5289 \\
\hline Bandwidth & $1 / 3$ & 1 & 7 & 2 & 0.164911216 & 0.1582 \\
\hline Delay Tolerance & $1 / 9$ & $1 / 7$ & 1 & $1 / 5$ & 0.041457905 & 0.0366 \\
\hline Delivery probability & $1 / 7$ & $1 / 2$ & 5 & 1 & 0.280751063 & 0.2763 \\
\hline
\end{tabular}

$\lambda_{\max }=4.178069312 ; \mathrm{CI}=0.059356437 ; \mathrm{CR}=0.065951597<0.1$

This pairwise matrix also passes a consistency check, which means that priority is selected correctly.

\subsubsection{Service 2}

The next service is more for the urgent delivery of data. In this case, the delay-tolerant indicator is about 3 hours, and the data volume is 64TB. As before, Service $2\left(S_{2}\right)$ has similar attributes but different tendencies. This service includes real-time applications, such as Video-on-Demand. These services are delay-sensitive and, therefore, cannot be delayed for more than 3 hours. However, due to the large volume of data, we still grant more importance to energy efficiency and delay attributes than other attributes. It is the service class with the highest QoS requirements, and it switches from one network to another quickly as per users' profiles, such as telephony speech, VoIP, video conferencing, and other real-time activities. If a user is connected to WLAN and loses connection, they can then switch to UMTS for QoS. The same procedure will be followed for all attributes for Service 2, as defined in Tables 6-8.

Table 6. Pairwise Comparison Utility matrix as per importance scale.

\begin{tabular}{ccccc}
\hline Attributes & $\begin{array}{c}\text { Energy } \\
\text { Efficiency }\end{array}$ & Bandwidth & $\begin{array}{c}\text { Delay } \\
\text { Tolerance }\end{array}$ & $\begin{array}{c}\text { Delivery } \\
\text { Probability }\end{array}$ \\
\hline Energy Efficiency & 1 & 7 & 1 & 5 \\
\hline Bandwidth & $1 / 7$ & 1 & $1 / 7$ & 2 \\
\hline Delay Tolerance & 1 & 7 & $1 / 7$ & 7 \\
\hline $\begin{array}{c}\text { Delivery } \\
\text { probability }\end{array}$ & $1 / 5$ & $1 / 2$ & 1 \\
\hline
\end{tabular}


Table 7. Normalized score table for all the attributes with the weight factor.

\begin{tabular}{cccccc}
\hline Attributes & $\begin{array}{c}\text { Energy } \\
\text { Efficiency }\end{array}$ & Bandwidth & $\begin{array}{c}\text { Delay } \\
\text { Tolerance }\end{array}$ & $\begin{array}{c}\text { Delivery } \\
\text { Probability }\end{array}$ & $\begin{array}{c}\text { Criteria } \\
\text { Weight }\end{array}$ \\
\hline $\begin{array}{c}\text { Energy } \\
\text { Efficiency }\end{array}$ & 1 & 7 & 1 & 5 & 0.42274576 \\
\hline Bandwidth & $1 / 7$ & 1 & $1 / 7$ & 2 & 0.08567345 \\
\hline $\begin{array}{c}\text { Delay } \\
\text { Tolerance }\end{array}$ & 1 & 7 & 1 & 7 & 0.45678945 \\
\hline $\begin{array}{c}\text { Delivery } \\
\text { probability }\end{array}$ & $1 / 5$ & $1 / 2$ & $1 / 7$ & 1 & 0.06435676 \\
\hline
\end{tabular}

Table 8. Normalized score table with priority vector.

\begin{tabular}{ccccccc}
\hline Attributes & $\begin{array}{c}\text { Energy } \\
\text { Efficiency }\end{array}$ & Bandwidth & $\begin{array}{c}\text { Delay } \\
\text { Tolerance }\end{array}$ & $\begin{array}{c}\text { Delivery } \\
\text { Probability }\end{array}$ & $\begin{array}{c}\text { Critera } \\
\text { Weight }\end{array}$ & $\begin{array}{c}\text { Priority } \\
\text { Vector }\left(\boldsymbol{P}_{w}\right)\end{array}$ \\
\hline $\begin{array}{c}\text { Energy } \\
\text { Efficiency }\end{array}$ & 1 & 7 & 1 & 5 & 0.42274576 & 0.4163 \\
\hline Bandwidth & $1 / 7$ & 1 & $1 / 7$ & 2 & 0.08567345 & 0.0782 \\
\hline $\begin{array}{c}\text { Delay } \\
\text { Tolerance }\end{array}$ & 1 & 7 & 1 & 7 & 0.45678945 & 0.4455 \\
\hline $\begin{array}{c}\text { Delivery } \\
\text { probability }\end{array}$ & $1 / 5$ & $1 / 2$ & $1 / 7$ & 1 & 0.06435676 & 0.0599 \\
\hline
\end{tabular}

$\lambda_{\text {max }}=4.156390957 ; \mathrm{CI}=0.052130319 ; \mathrm{CR}=0.057922576<0.1$.

This pairwise matrix also passes a consistency check, which means that priority is selected correctly. We have calculated the weight for all three types of services by users' preferences for different attributes.

\subsubsection{Service 3}

The next service is different from the previous two. In this case, the delay tolerance is 6 hours and the data volume is $32 \mathrm{~TB}$. Service $3\left(S_{3}\right)$ has consistent attributes but different characteristics. This service is not that low in data volume, compared to the others. These services are delay-sensitive and, therefore, cannot be delayed for more than 6 hours. In this case, the user has all three options to disseminate data. The controller will first look for all the network options, including WLAN, UMTS, and whether there are buses available to carry data within the given timeframe. The same procedure will be followed for all attributes, as defined in Tables 9-11:

Table 9. Pairwise Comparison Utility matrix as per importance scale.

\begin{tabular}{ccccc}
\hline Attributes & $\begin{array}{c}\text { Energy } \\
\text { Efficiency }\end{array}$ & Bandwidth & $\begin{array}{c}\text { Delay } \\
\text { Tolerance }\end{array}$ & $\begin{array}{c}\text { Delivery } \\
\text { Probability }\end{array}$ \\
\hline Energy Efficiency & 1 & $1 / 6$ & $1 / 6$ & $1 / 7$ \\
\hline Bandwidth & 6 & 1 & 3 & 1 \\
\hline Delay Tolerance & 6 & $1 / 3$ & 5 & $1 / 5$ \\
\hline $\begin{array}{c}\text { Delivery } \\
\text { probability }\end{array}$ & 7 & 1 & 1 \\
\hline
\end{tabular}


Table 10. Normalized score table for all the attributes with the weight factor.

\begin{tabular}{cccccc}
\hline Attributes & $\begin{array}{c}\text { Energy } \\
\text { Efficiency }\end{array}$ & Bandwidth & $\begin{array}{c}\text { Delay } \\
\text { Tolerance }\end{array}$ & $\begin{array}{c}\text { Delivery } \\
\text { Probability }\end{array}$ & $\begin{array}{c}\text { Criteria } \\
\text { Weight }\end{array}$ \\
\hline $\begin{array}{c}\text { Energy } \\
\text { Efficiency }\end{array}$ & 1 & $1 / 6$ & $1 / 6$ & $1 / 7$ & 0.05355183 \\
\hline Bandwidth & 6 & 1 & 3 & 1 & 0.36439882 \\
\hline $\begin{array}{c}\text { Delay } \\
\text { Tolerance }\end{array}$ & 6 & $1 / 3$ & 1 & $1 / 5$ & 0.15369319 \\
\hline $\begin{array}{c}\text { Delivery } \\
\text { probability }\end{array}$ & 7 & 1 & 5 & 1 & 0.4540202 \\
\hline
\end{tabular}

Table 11. Normalized score table with priority vector

\begin{tabular}{ccccccc}
\hline Attributes & $\begin{array}{c}\text { Energy } \\
\text { Efficiency }\end{array}$ & Bandwidth & $\begin{array}{c}\text { Delay } \\
\text { Tolerance }\end{array}$ & $\begin{array}{c}\text { Delivery } \\
\text { Probability }\end{array}$ & $\begin{array}{c}\text { Criteria } \\
\text { Weight }\end{array}$ & $\begin{array}{c}\text { Priority } \\
\text { Vector }\left(\boldsymbol{P}_{w}\right)\end{array}$ \\
\hline $\begin{array}{c}\text { Energy } \\
\text { Efficiency }\end{array}$ & 1 & $1 / 6$ & $1 / 6$ & $1 / 7$ & 0.05355183 & 0.0459 \\
\hline Bandwidth & 6 & 1 & 3 & 1 & 0.36439882 & 0.3613 \\
\hline $\begin{array}{c}\text { Delay } \\
\text { Tolerance }\end{array}$ & 6 & $1 / 3$ & 1 & $1 / 5$ & 0.15369319 & 0.1499 \\
\hline $\begin{array}{c}\text { Delivery } \\
\text { probability }\end{array}$ & 7 & 1 & 5 & 1 & 0.45402002 & 0.4429 \\
\hline
\end{tabular}

$\lambda_{\text {max }}=4.234869383 ; \mathrm{CI}=0.078289794 ; \mathrm{CR}=0.08698866<0.1$.

This pairwise matrix also passes a consistency check, which means that priority is selected correctly. We have given importance to different attributes as per different services. Next, we calculated criteria weight for all the attributes and then, added priority vector to all of the attributes as per different services. Based on these calculations, next, we will rank our network for different services.

\subsection{Network Selection for Different Services}

We have discussed the AHP procedure and utility theory for all the attributes' weighings and preferences. Now, the AHP procedure will help us weigh different attributes for all of our services. In our work, we define the traditional and vehicular networks as alternatives to choose from and the available list is $I_{a n}=(W, U, V)$. Algorithm 1 illustrates the whole process for optimal network selection based upon different services.

There is a list of available networks $I_{a n}=(W, U, V)$ to choose from. We collect all the network attributes in list $I_{a n}=a_{1}, a_{2} \ldots a_{n}$, named energy-efficient $e_{u}$, delivery probability $d p_{u}$, delay demand $d_{u}$, and available bandwidth $b_{i}$ of both networks. Then, we follow all the steps to rank the network among all the networks, as per different services. We use this network-selection technique only to offer the best option as per their requirements to maintain QoS. It is mandatory to pass the consistency check in AHP in order to obtain an accurate judgment matrix. If any of the matrices fail to pass this check, the user will have to give preferences to the design matrix. We will first analyze public vehicle distributions near bus stops to know the availability of networks to choose from, and then further evaluate the performance of all networks for different services. Figure 12 illustrates the criteria weights given to all the attributes as per different services. For example, as discussed before, Service 1 has delay-tolerant features and will be considered an energy-efficient data-dissemination network. Therefore, the criteria weight will be allocated more heavily on the EE attribute. In such a way, all the weights are distributed as per the service profile. The priority vector is calculated for all the services as per different attributes as shown in Figure 13. The final score is calculated as discussed in Figure 14. Utility functions are defined already for all the attributes. For all of these services, we will have different utility values. We will score our network based upon the maximum utility value for all the services. 

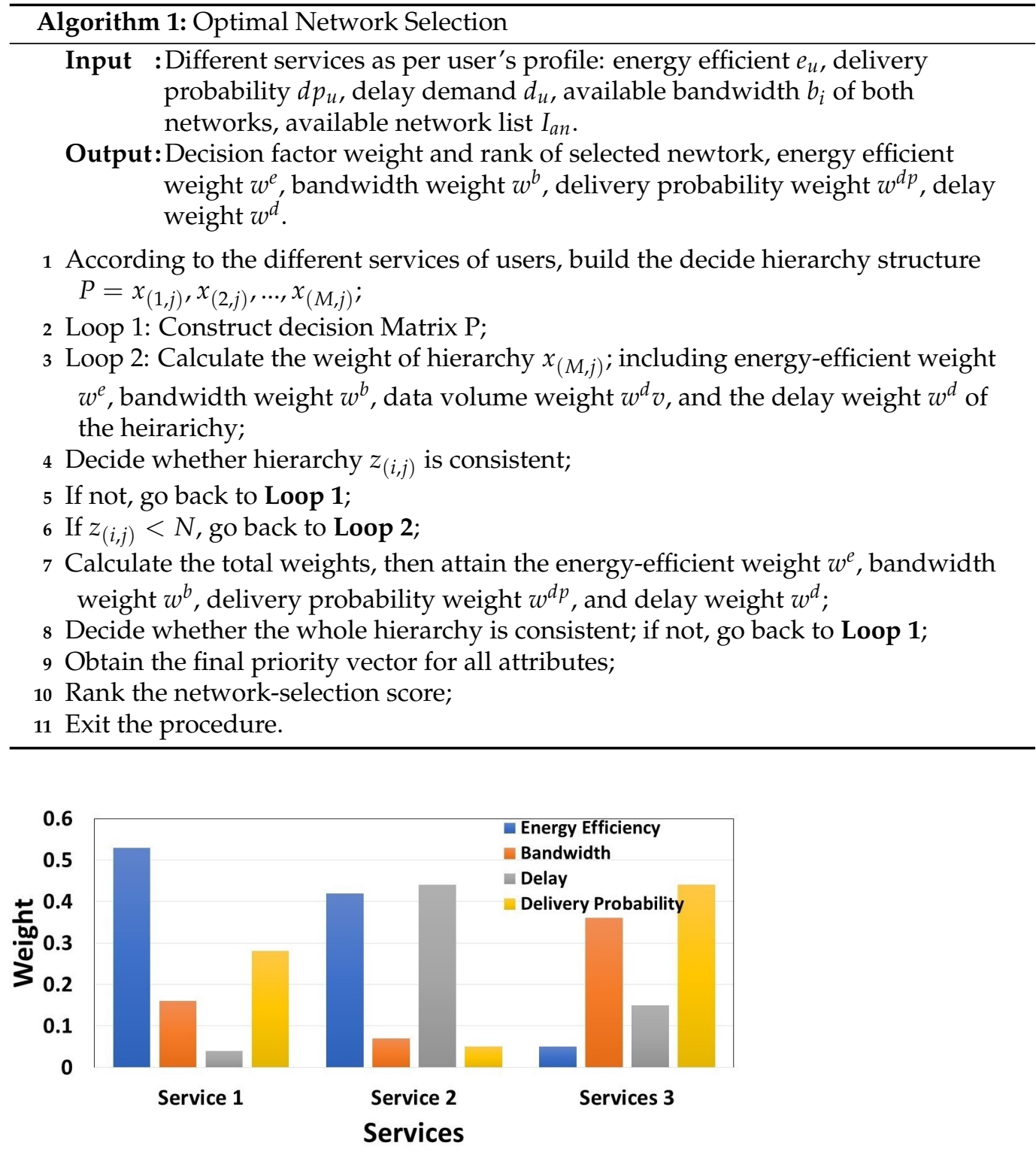

Figure 12. Weight distributed to all attributes as per different services.

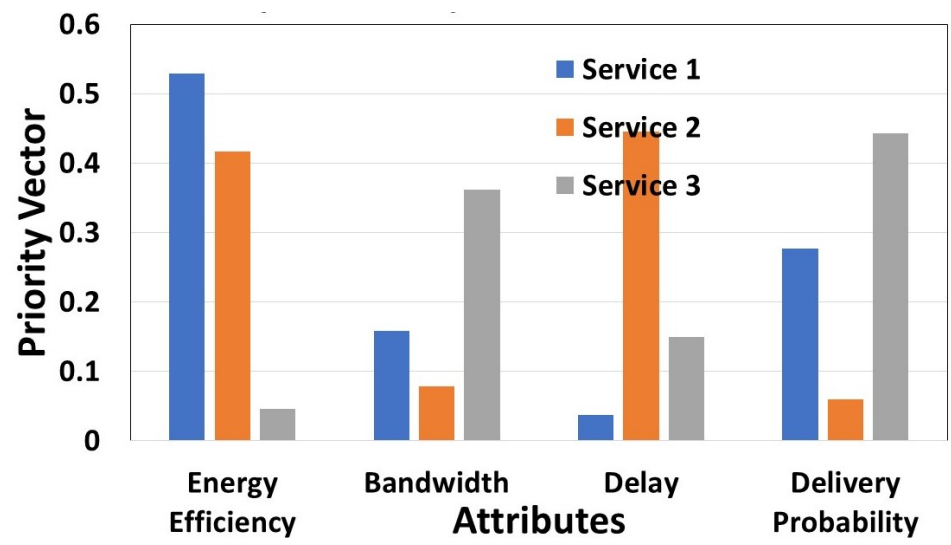

Figure 13. Priority vector for all services. 


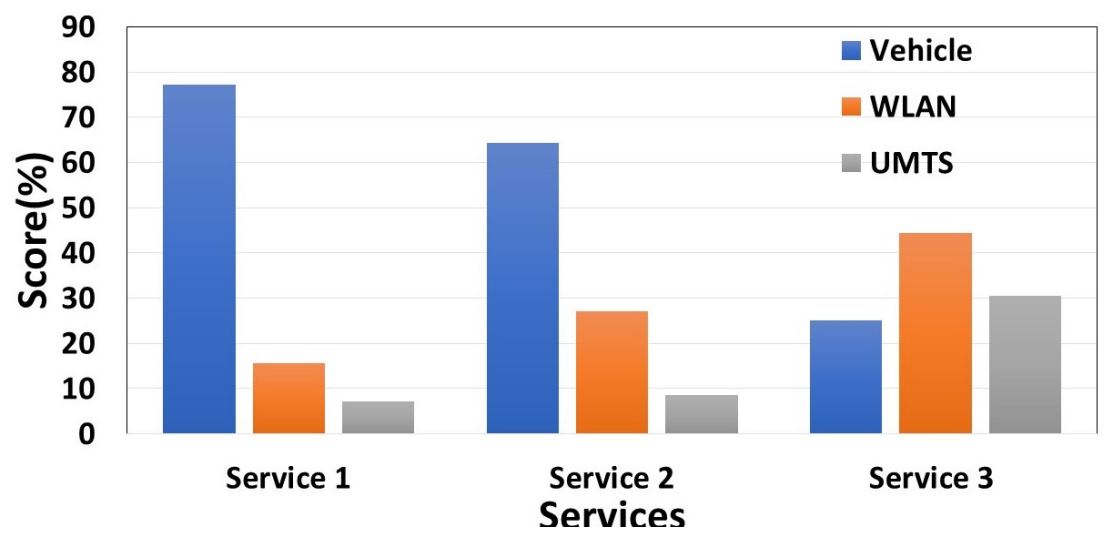

Figure 14. Network ranking for all services.

The AHP score is the final ranking of all the services as per the preferences given for all the attributes. For service 1, the ranking order is Vehicle $>$ WLAN > UTMS, as the data is delay-tolerant and can be carried by vehicles for energy-efficient data-dissemination, as shown in Figure 14. However, service 2, which is delay-sensitive but for a larger volume than service 1, also gives preference to vehicular networks for data-delivery, rather than WLAN and UMTS, with a ranking order Vehicle $>$ WLAN $>$ UTMS. For service 3, the network ranking preference is in the order of WLAN > UMTS > Vehicle for the urgent delivery of data so as to sustain QoS. In network dynamics, the most important factor is packet delivery without loss. Our heterogeneous network architecture guarantees the delivery of data by using any of the available networks and considering different attributes.

\subsection{Case Study II}

We conduct a numerical example to allocate different demands generated from DC on buses to carry data until the destination, while minimizing energy consumption. We consider 16 demands generated randomly from different bus stops to deliver their data carried by bus.

As shown in Figure 15, there are many bus stops around and demands have been allocated to the DC for data allocation onto the suitable bus. The controller will make an energy-efficient decision based upon Equation 13. DC is the central depot, where the bus begins and finishes its journey. As per Table 12, different data demands are generated for data being delivered from the parent stop to the destination stop. The controller identifies 4 buses, B1, B2, B3, and B4, to fulfill all demands with an energy-efficient solution. The total capacity of each bus is 150TB. The distance to each bus stop has been given from the central depot or source bus stop.

The demands must not exceed the maximum capacity of the bus. We use CVRP instances from the past and solve using the Cplex optimization solver. The Capacitated Vehicle Routing Problem is an NP-hard problem that can be solved exactly only for small instances. We have tested our objective function and observed an optimal solution while minimizing energy consumption. We assume that buses are available to carry data towards each bus stop. However, we will be calculating energy consumption while sending data through a traditional network to show via comparison that PTDD is an energy-efficient solution for delay-tolerant data applications. 


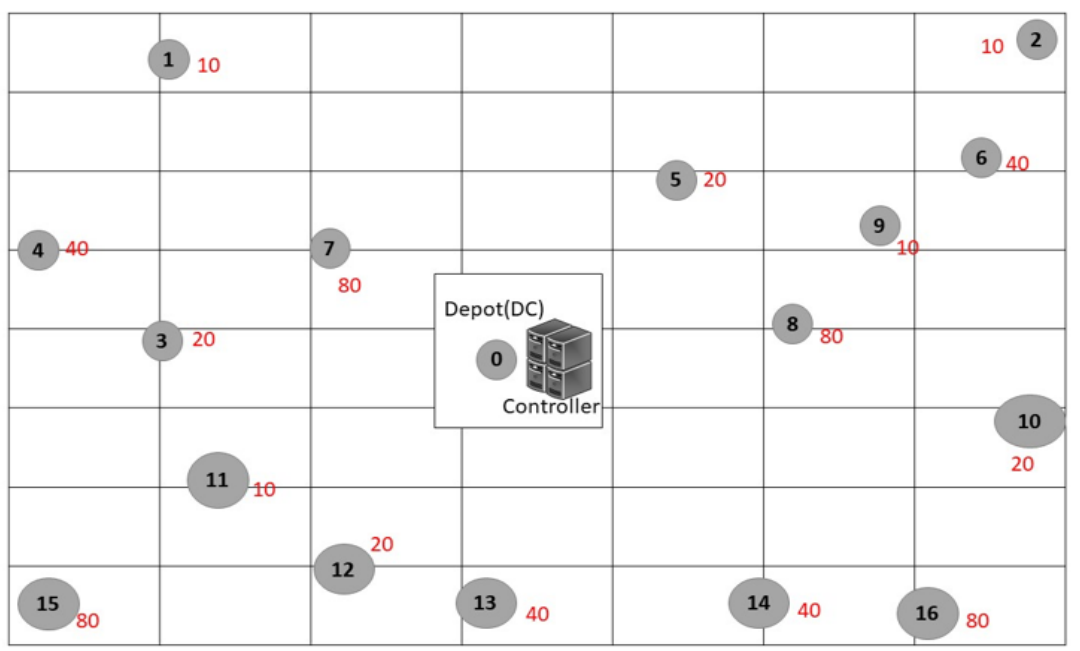

Figure 15. Proposed scheme for the problem.

Table 12. Demands from all bus stops for data allocation

\begin{tabular}{|c|c|c|c|}
\hline $\begin{array}{c}\text { Number } \\
\text { of Buses per Day }\end{array}$ & $\begin{array}{c}\text { Demands from } \\
\text { Destination Stop (TB) }\end{array}$ & $\begin{array}{l}\text { Distance from } \\
\text { Depot }(0)(\mathrm{Km})\end{array}$ & $\begin{array}{c}\text { Bus } \\
\text { Capacity (TB) }\end{array}$ \\
\hline 1 & 10 & 5.48 & 150 \\
\hline 2 & 10 & 7.76 & 150 \\
\hline 3 & 20 & 6.95 & 150 \\
\hline 4 & 40 & 5.82 & 150 \\
\hline 5 & 20 & 2.74 & 150 \\
\hline 6 & 40 & 5.02 & 150 \\
\hline 7 & 80 & 1.94 & 150 \\
\hline 8 & 80 & 3.08 & 150 \\
\hline 9 & 10 & 1.94 & 150 \\
\hline 10 & 20 & 5.36 & 150 \\
\hline 11 & 10 & 5.02 & 150 \\
\hline 12 & 20 & 3.88 & 150 \\
\hline 13 & 40 & 3.54 & 150 \\
\hline 14 & 40 & 4.68 & 150 \\
\hline 15 & 80 & 7.76 & 150 \\
\hline 16 & 80 & 6.62 & 150 \\
\hline
\end{tabular}

As per the defined parameters, we have allocated data onto four buses that fulfill all requirements while minimizing energy consumption and returning to the source bus stop or depot after finishing their trips. We have defined all the bus routes with the optimal selected route for data allocation in Figure 16. All the buses have a maximum $150 \mathrm{~TB}$ capacity to carry and allocate data to all bus stops. 


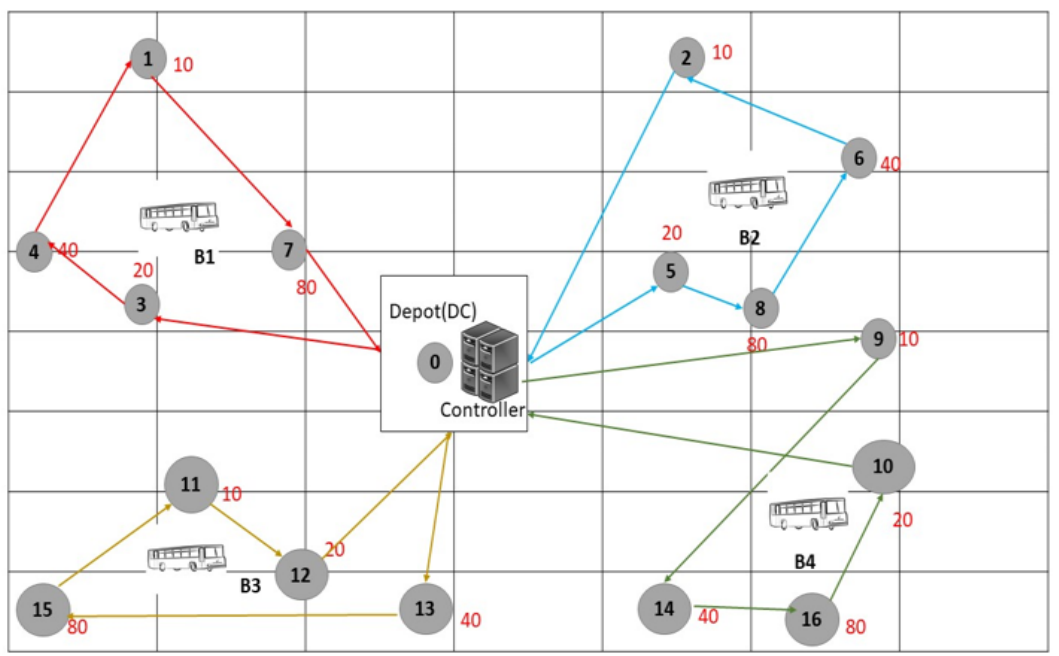

Figure 16. Data allocation onto each bus stop through buses.

Table 13 shows the computation results of all the buses traversing all the bus stops in a unidirectional format and the total distance covered during each trip.

Table 13. Set of test trips with the number of bus stops.

\begin{tabular}{ccc}
\hline Bus Number & Selected Route & $\begin{array}{c}\text { Total Distance Covered } \\
\text { During the Trip }\end{array}$ \\
\hline B1 & $0-3-4-1-7-0$ & $12 \mathrm{~km}$ \\
\hline B2 & $0-5-8-6-2-0$ & $13 \mathrm{~km}$ \\
\hline B3 & $0-13-15-11-12-0$ & $12 \mathrm{~km}$ \\
\hline B4 & $0-9-14-16-10-0$ & $13 \mathrm{~km}$ \\
\hline
\end{tabular}

In our analysis, we have used 16 stops, which will be covered by four buses, to fulfill their demands being allocated from a DC to deliver data. In Figures 17 and 18, we can see that it is possible to disseminate data either from the core traditional network or PTDD in the heterogeneous network. However, if we have delay-tolerant data and can utilize public transport, PTDD is an energy-efficient solution. Bus stops 1 and 2 have demands of 10 TB, bus stops 3 and 5 have demands of $20 \mathrm{~TB}$, bus stops 4 and 6 have demands of $40 \mathrm{~TB}$, and bus stops 7 and 8 have demands of 80 TB.

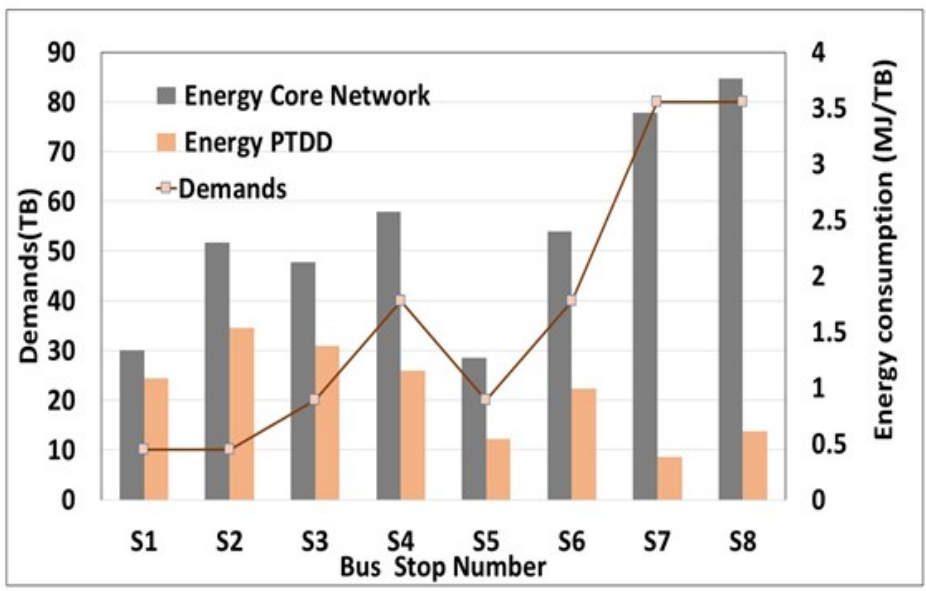

Figure 17. Energy consumption vs. bus stop number for generated demands. 


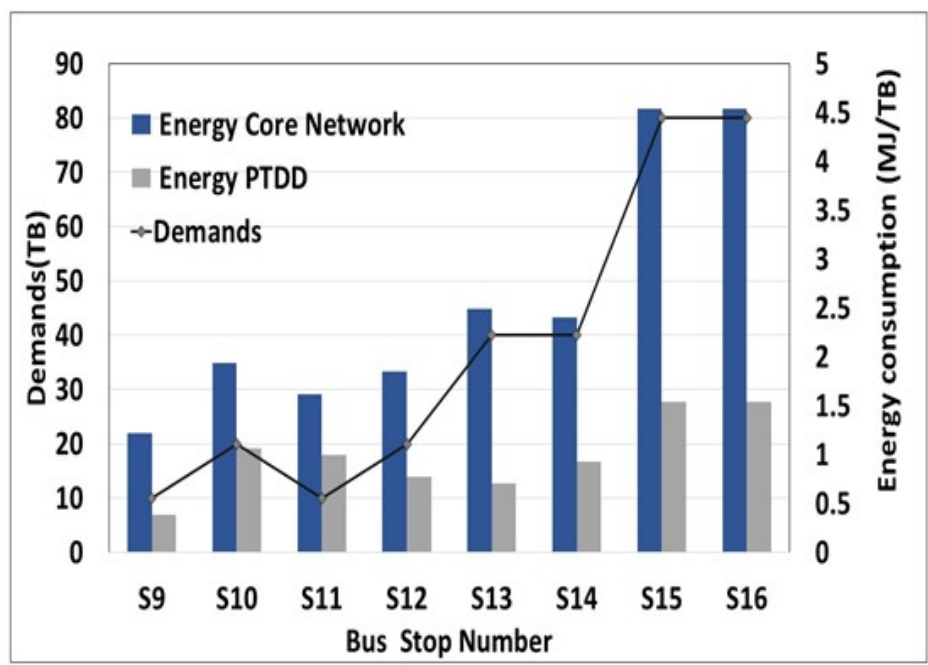

Figure 18. Energy consumption vs. bus stop number for generated demands.

As shown in Figure 18, bus stops 9 and 10 have demands for 10TB data, bus stops 10 and 12 demand 20 TB data, bus stops 13 and 14 demand 40TB data, and bus stops 15 and 16 have demands for $80 \mathrm{~TB}$ data. The bus will carry and deliver data at each bus stop as per their demands. For the maximum demands of $80 \mathrm{~TB}$, we can analyze that the core network consumes 33\% more energy than PTDD for data transmission.

A bus that stops for 500 seconds, for a total 60 buses, can offload $64.8 \mathrm{~GB} /$ day, with an effective throughput of $22.03 \mathrm{MB} / \mathrm{s}$. Moreover, transmission performance is also highly influenced by the number of buses in a day and the stoppage time at a bus stop. Figure 19 shows the transmission performance of each network for different data rates. We have considered that public transport will be using IEEE 802.11ac as a network interface for data allocation. However, for comparison, we use the bandwidth of $512 \mathrm{MB} / \mathrm{s}$ and $1 \mathrm{~GB} / \mathrm{s}$ in the traditional network to have a real difference. The outcome demonstrates that our proposed public transport network outperforms the traditional core network.

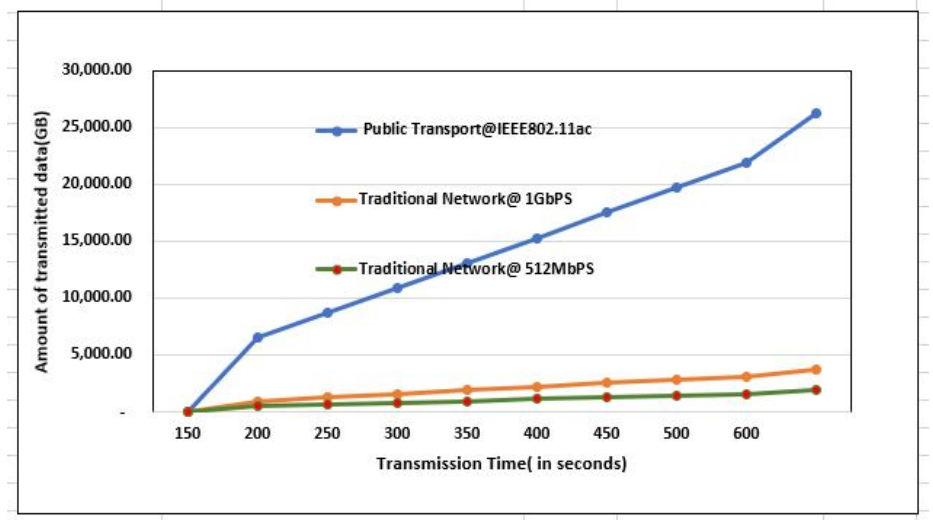

Figure 19. Transmission performance.

\section{Discussion}

We analyzed the various perspectives of traditional networks and every network has their standpoint and mode of communication. These networks rely mostly on big data analytics in the design of data communication networks. Therefore, these big data applications' survival would not be possible without the underlying support of networking, due to their extremely large volume and computing complexity. To elaborate further, we represent the three digital laws, Kryder's law, Moore's law, and Neilson's law, in Figure 20, which states that new products come into the market with each passing year 
with new technology. The basic idea of Kryder's law is to double the storage capacity every 12 months. Moore's law is somewhat like Kryder, but works on the processing speed of chips, which is doubled every 18 months. Moving forward to Neilson's law, which estimates that bandwidth doubles every twenty-one months, this last component of digital experience lags for both storage and processing speed. These three laws clearly explain that whatever new network technology comes onto the market, the available data (in online storage) is never fully accessed by the new network technology and the end-users. There will always be a gap between the available bandwidth and the available data/information storage online. This big data need will never be satisfied with internet technology.

This biggest challenge encourages the search for more connectivity options. Several attempts [41,42] have been made in developing efficient, sustainable, and integrated (wired/wireless) networks. The opportunistic network is one of the techniques to overcome this problem while disseminating data in-store and in a forward manner by connecting mobile devices. Many researchers have already discussed the concept of vehicular networks used as data carriers, as is discussed in the literature. However, we are contributing to existing work by introducing an alternative communication PTDD for sustainable datadissemination via the introduction of a third layer of the public transport network to complement the conventional wired and wireless networks. For delay-tolerant data needs, our approach aims to better utilize the existing smart public vehicles and their parking spots with local storage to offload and upload data, thereby lowering the energy consumption while successfully delivering data.

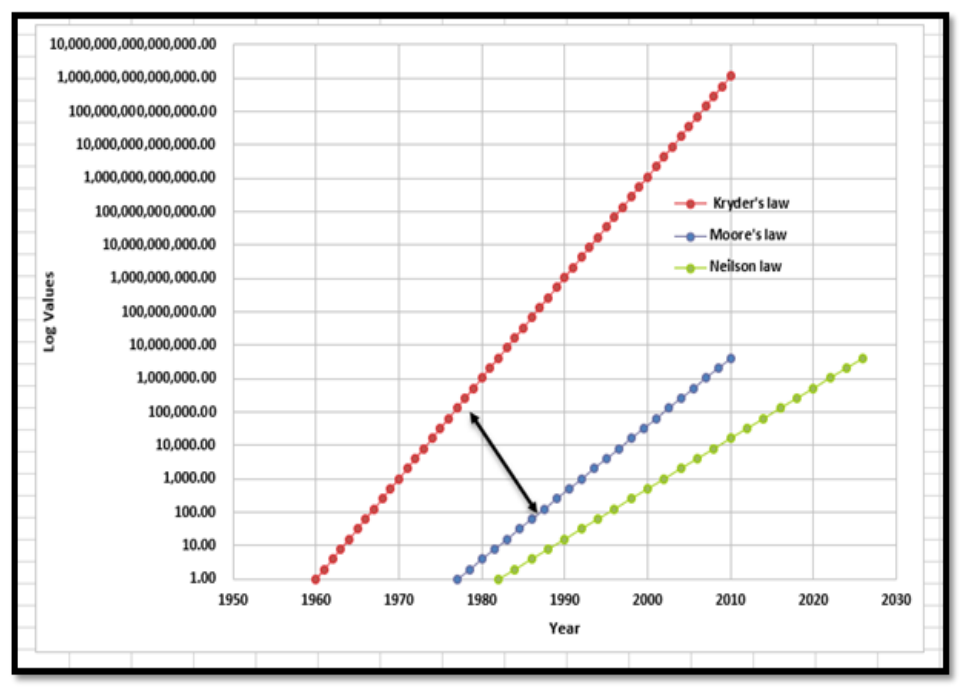

Figure 20. Kryder's, Moore's, and Nielsen's laws.

However, our work combines all of the networks, such as wired, wireless, and public transport, to use and switch according to the requirements of different services. The performance of our architecture was evaluated in two stages. First is the network selection among different networks, and second is when public transport is selected; in this stage, data is allocated onto these buses as per their fixed route. We evaluated our results using the SAS optimization tool while sending data using both networks and minimizing energy cost.

Our main, fundamental questions are: under which conditions would public transport will be selected among other networks? Relatedly, we consider how data will be allocated onto these buses. The existing literature has used many methods and compared them to show differentiation and their respective selection methods. In our work, the main implication is that the utility values are defined for all the attributes for the user's satisfaction, along with the AHP method for networks ranking. There is a vast amount of literature on existing networkselection techniques among different networks; we have utilized their concepts for public transport network selection based upon different user's demands for energy-efficiency. If we talk about the practical implications of our proposed system, any 
unexpected disaster-either naturally occurring or caused by human actions-firstly results in damage to the communication medium, although many of the technologies have been introduced for disaster management and attempt to connect the affected area with the rest of the world. However, in the post-disaster scenario, compared to the building and any bus stop, vehicles can be quickly moved to the affected area. In particular, public transport is firstly available to fulfill people's basic needs. Therefore, our PTDD can be efficiently utilized as a mobile communication backbone in disaster management.

\section{Conclusions and Future Work}

In this paper, we have presented an alternative communication channel PTDD for sustainable data-dissemination via the introduction of public transport networks to complement conventional wired and wireless networks. For delay-tolerant data needs, our approach aims to better utilize the PTDD and their parking spots/bus stops with local storage to offload and upload data. The controller used the MADM method to make an optimal network-selection decision among different networks and based on different services. The main implication is that the utility values are defined for all the attributes for the user's satisfaction, along with the AHP method for network ranking. We used Auckland's public transport network to prove that buses/public vehicles can be used as a data carrier. The results presented show the network ranking trends among all networks for different kinds of services. The second case study was presented using CVRP, which helped to minimize energy consumption with a fixed capacity of buses to allocate data onto each bus stop. This work provides strong evidence that significant energy savings can be achieved while still guaranteeing data delivery. The results presented here appear to be reasonable and promising, which ultimately proves that public transport can be used as another alternative communication network for delay-tolerant data needs. However, the proposed method could be affected by the highly dynamic changes in network topologies.

We have analysed PTDD with a static dataset; for future work, the network should be developed with dynamic factors such as traffic, weather, passenger flow data, etc., for realtime changes in the network. An analytical model for dynamic behaviors of bus movement would be a good future contribution. In terms of the future potential of applications, our system can be used in video surveillance systems. The transport agency has deployed people with cameras to record drivers illegally going into T3/T2 lanes. The public transport belongs to the same transport agency; thus, if these cameras can be deployed onto bus stops, then these buses can be utilized for carrying that accumulated data to the main center. These videos are not urgent and can be delayed up to hours for delivery. Hence, PTDD can be utilized efficiently to alleviate this network congestion case and to improve energy efficiency. However, the privacy and security part is lacking in our proposed work, and we will consider those aspects as future work and an extension of our proposed architecture.

Author Contributions: R.M. modeled the multi-attribute decision making for energy-efficient network selection in a heterogeneous network and adopted CVRP for optimal vehicle selection, implemented the case study, and analyzed the data under the supervision of W.L., X.L., J.G., and P.H.J.C. The manuscript was drafted by R.M., and was revised and proofread by W.L., X.L., J.G., and P.H.J.C. All authors have read and agreed to the published version of the manuscript.

Funding: This research received no external funding.

Data Availability Statement: Not Applicable, the study does not report any data.

Conflicts of Interest: The authors declare no conflict of interest.

\section{References}

1. Dehghani-Sanij, A.R.; Al-Haq, A.; Bastian, J.; Luehr, G.; Nathwani, J.; Dusseault, M.B.; Leonenko, Y. Assessment of current developments and future prospects of wind energy in Canada. Sustain. Energy Technol. Assess. 2022, 50, 101819. [CrossRef]

2. Babiceanu, R.F.; Seker, R. Big Data and virtualization for manufacturing cyber-physical systems: A survey of the current status and future outlook. Comput. Ind. 2016, 81, 128-137. [CrossRef] 
3. Munjal, R.; Liu, W.; Li, X.J.; Gutierrez, J.; Chong, P.H.J. Telco asks transp: Can you give me a ride in the era of big data? In Proceedings of the 2017 IEEE Conference on Computer Communications Workshops (INFOCOM WKSHPS), Atlanta, GA, USA, 1-4 May 2017; IEEE: Piscataway, NJ, USA, 2017; pp. 766-771.

4. Deebak, B.D. Cooperative Mobile Traffic Offloading in Mobile Edge Computing for 5G HetNet IoT Applications In Real-Time Intelligence for Heterogeneous Networks; Springer: Berlin/Heidelberg, Germany, 2021; pp. 43-58.

5. Han, C.; Harrold, T.; Armour, S.; Krikidis, I.; Videv, S.; Grant, P.M.; Haas, H.; Thompson, J.S.; Ku, I.; Wang, C.X. Green radio: Radio techniques to enable energy-efficient wireless networks. IEEE Commun. Mag. 2011, 49, 46-54. [CrossRef]

6. Wang, X.; Vasilakos, A.V.; Chen, M.; Liu, Y.; Kwon, T.T. A survey of green mobile networks: Opportunities and challenges. Mob. Netw. Appl. 2012, 17, 4-20. [CrossRef]

7. Kelly, T.; Head, S. ICTs and Climate Change. In ITU-T Technology, Tech. Rep; 2007. Available online: https:/ / www.itu.int/ITU-D/ cyb/events/2008/geneva/docs/kelly-icts_and_climate_change-may2008.pdf (accessed on 22 December 2021).

8. Chen, Y. Great project overview,(slides) In Proceedings of the GreenTouch Open Forum (2011), Seoul, Korea, 8 April 2011.

9. Fettweis, G.; Zimmermann, E. ICT energy consumption-trends and challenges. In Proceedings of the 11th International Symposium on Wireless Personal Multimedia Communications, Lapland, Finland, 8-11 September 2008; Volume 2, p. 6.

10. McGreehan, J. Climate change and natural resources: What contribution can wireless communications make? In UK Green Wireless Communication-Future Trend and Technology; Springer: Berlin/Heidelberg, Germany, 2009; Volume 25, pp. 1-7.

11. Etoh, M.; Ohya, T.; Nakayama, Y. Energy consumption issues on mobile network systems. In Proceedings of the 2008 International Symposium on Applications and the Internet, SAINT 2008, Turku, Finland, 28 July-1 August 2008; IEEE: Piscataway, NJ, USA, 2008; pp. 365-368.

12. Li, M.; Si, P.; Zhang, Y. Delay-tolerant data traffic to software-defined vehicular networks with mobile edge computing in smart city. IEEE Trans. Veh. Technol. 2018, 67, 9073-9086. [CrossRef]

13. Baron, B.; Spathis, P.; Rivano, H.; de Amorim, M.D.; Viniotis, Y.; Ammar, M.H. Centrally controlled mass data offloading using vehicular traffic. IEEE Trans. Netw. Serv. Manag. 2017, 14, 401-415. [CrossRef]

14. Baron, B.; Spathis, P.; Rivano, H.; de Amorim, M.D. Vehicles as big data carriers: Road map space reduction and efficient data assignment. In Proceedings of the 2014 IEEE 80th Vehicular Technology Conference (VTC2014-Fall), Vancouver, BC, Canada, 14-17 September 2014; p. 1-5.

15. Wang, T.; Li, P.; Wang, X.; Wang, Y.; Guo, T.; Cao, Y. A comprehensive survey on mobile data offloading in heterogeneous network. Wirel. Netw. 2019, 25, 573-584. [CrossRef]

16. Bendaoud, F. A modified-SAW for network selection in heterogeneous wireless networks. ECTI Trans. Electr. Eng. Electron. Commun. 2017, 15, 8-17.

17. Salih, Y.K.; See, O.H.; Ibrahim, R.W.; Yussof, S.; Iqbal, A. A user-centric game selection model based on user preferences for the selection of the best heterogeneous wireless network. Ann. -Telecommun.-Ann. Télécommun. 2015, 70, 239-248. [CrossRef]

18. Sgora, A.; Vergados, D.D.; Chatzimisios, P. An access network selection algorithm for heterogeneous wireless environments. In Proceedings of the IEEESymposium on Computers and Communications, Riccione, Italy, 22-25 June 2010; IEEE: Piscataway, NJ, USA, 2010; pp. 890-892.

19. Wang, L.; Kuo, G.S.G. Mathematical modeling for network selection in heterogeneous wireless networks-A tutorial. IEEE Commun. Surv. Tutor. 2012, 15, 271-292. [CrossRef]

20. Bi, T.; Yuan, Z.; Trestian, R.; Muntean, G.M. URAN: Utility-based reputation-oriented access network selection strategy for HetNets. In Proceedings of the 2015 IEEE International Symposium on Broadband Multimedia Systems and Broadcasting, Ghent, Belgium, 17-19 June 2015; IEEE: Piscataway, NJ, USA, 2015; pp. 1-6.

21. Çalhan, A.; Çeken, C. An optimum vertical handoff decision algorithm based on adaptive fuzzy logic and genetic algorithm. Wirel. Pers. Commun. 2012, 64, 647-664. [CrossRef]

22. Fu, S.; Li, J.; Li, R.; Ji, Y. A game theory based vertical handoff scheme for wireless heterogeneous networks. In Proceedings of the 2014 10th International Conference on Mobile Ad-hoc and Sensor Networks, Maui, HI, USA, 19-21 December 2014; IEEE: Piscataway, NJ, USA, 2014; pp. 220-227.

23. Abid, M.; Yahiya, T.A.; Pujolle, G. A utility-based handover decision scheme for heterogeneous wireless networks. In Proceedings of the 2012 IEEE Consumer Communications and Networking Conference (CCNC), Las Vegas, NV, USA, 14-17 January 2012; IEEE: Piscataway, NJ, USA, 2012; pp. 650-654.

24. Goyal, R.K.; Kaushal, S.; Sangaiah, A.K. The utility based non-linear fuzzy AHP optimization model for network selection in heterogeneous wireless networks. Appl. Soft Comput. 2018, 67, 800-811. [CrossRef]

25. Jiang, D.; Huo, L.; Lv, Z.; Song, H.; Qin, W. A joint multi-criteria utility-based network selection approach for vehicle-toinfrastructure networking. IEEE Trans. Intell. Transp. Syst. 2018, 19, 3305-3319. [CrossRef]

26. Poirot, V.; Ericson, M.; Nordberg, M.; Andersson, K. Energy efficient multi-connectivity algorithms for ultra-dense $5 \mathrm{G}$ networks. Wirel. Netw. 2020, 26, 2207-2222. [CrossRef]

27. Sede, M.; Li, X.; Li, D.; Wu, M.Y.; Li, M.; Shu, W. Routing in large-scale buses ad hoc networks. In Proceedings of the 2008 IEEE Wireless Communications and Networking Conference, Las Vegas, NV, USA, 31 March-3 April 2008; IEEE: Piscataway, NJ, USA, 2008; pp. 2711-2716.

28. Xian, Y.; Huang, C.T.; Cobb, J. Look-ahead routing and message scheduling in delay-tolerant networks. Comput. Commun. 2011, 34, 2184-2194. [CrossRef] 
29. Komnios, I.; Tsapeli, F.; Gorinsky, S. Cost-effective multi-mode offloading with peer-assisted communications. Ad Hoc Netw. 2015, 25, 370-382. [CrossRef]

30. Kassar, M.; Kervella, B.; Pujolle, G. An overview of vertical handover decision strategies in heterogeneous wireless networks. Comput. Commun. 2008, 31, 2607-2620. [CrossRef]

31. Song, Q.; Jamalipour, A. A network selection mechanism for next generation networks. In Proceedings of the IEEE International Conference on Communications, ICC 2005, Seoul, Korea, 16-20 May 2005; IEEE: Piscataway, NJ, USA, 2005; Volume 2, pp. 14181422.

32. Liang, G.; Guo, X.; Sun, G.; Fang, J. A User-Oriented Intelligent Access Selection Algorithm in Heterogeneous Wireless Networks. Comput. Intell. Neurosci. 2020, 2020, 8828355. [CrossRef]

33. Yu, H.; Ma, Y.; Yu, J. Network selection algorithm for multiservice multimode terminals in heterogeneous wireless networks. IEEE Access 2019, 7, 46240-46260. [CrossRef]

34. Munjal, R.; Liu, W.; Li, X.J.; Gutierrez, J. A Neural Network-Based Sustainable Data Dissemination through Public Transportation for Smart Cities. Sustainability 2020, 12, 10327. [CrossRef]

35. Munjal, R.; Liu, W.; Li, X.J.; Gutierrez, J. Big data offloading using smart public vehicles with software defined connectivity. In Proceedings of the 2019 IEEE Intelligent Transportation Systems Conference (ITSC), Auckland, New Zealand, 27-30 October 2019; IEEE: Piscataway, NJ, USA, 2019; pp. 3361-3366.

36. Poulliat, C. Mobile Data Offloading via Urban Public Transportation Networks. Ph.D. Thesis, Institut de Recherche en Informatique de Toulouse, Toulouse, France, 2017.

37. Nguyen-Vuong, Q.T.; Agoulmine, N.; Cherkaoui, E.H.; Toni, L. Multicriteria optimization of access selection to improve the quality of experience in heterogeneous wireless access networks. IEEE Trans. Veh. Technol. 2012, 62, 1785-1800. [CrossRef]

38. Saaty, T.L. Decision making with the analytic hierarchy process. Int. J. Serv. Sci. 2008, 1, 83-98. [CrossRef]

39. Vanier, D.; Tesfamariam, S.; Sadiq, R.; Lounis, Z. Decision models to prioritize maintenance and renewal alternatives. In Proceedings of the Joint International Conference on Computing and Decision Making in Civil and Building Engineering, Montréal, QC, Canada, 14-16 June 2006; pp. 14-16.

40. 2021. Available online: www.idc.com/ap/smartcities (accessed on 22 December 2021).

41. Heinzelman, W.R.; Kulik, J.; Balakrishnan, H. Adaptive protocols for information dissemination in wireless sensor networks. In Proceedings of the 5th annual ACM/IEEE International Conference on Mobile Computing and Networking, Seattle, WA, USA; ACM: New York, NY, USA, 15-19 August 1999; pp. 174-185.

42. Boukerche, A.; Darehshoorzadeh, A. Opportunistic routing in wireless networks: Models, algorithms, and classifications. ACM Comput. Surv. (CSUR) 2015, 47, 22. [CrossRef] 